\title{
Price Formation in the Indonesian Beef Industry: The Role of Policy Intervention
}

to obtain Ph.D. Degree in the International Ph.D. Program for Agricultural Sciences in Göttingen (IPAG) at the Faculty of Agricultural Science Georg-August Universität Göttingen

presented by Anisa Dwi Utami

born in Pekalongan, Indonesia

Göttingen, December 2016 
Referee : Prof. Dr. Bernhard Brümmer

Co-Referee : Prof. Stephan von Cramon-Taubadel

Date of oral examination : $30^{\text {th }}$ January 2017 


\section{Summary}

This dissertation aims to analyze price formation in Indonesian beef industry for the last 14 years, covering the period from 2002 to 2015 and focusing on the role of policy intervention. To this end, it provides empirical investigation on price transmission process in Indonesian beef industry through both spatial and vertical analyses. This dissertation contributes to the literature in two ways. First, it provides updated empirical evidence about the role of policy intervention in price transmission process in the beef industry, particularly in the context of developing country. Second, from the methodological aspect, this dissertation applies several new and different methods in price transmission analysis; i.e. the use of Regularized Bayesian Estimation Technique in the Threshold Vector Error Correction Model (TVECM) and Panel Cointegration Approach. Furthermore, to our knowledge, this dissertation is the first study that investigates price formation in Indonesian beef industry.

This dissertation consists of six chapters and involves four different analyses. The first analysis attempts to answer the question on how import policy affects domestic price formation in Indonesian beef industry by investigating the price transmission process between import and domestic prices. The empirical investigation is conducted using threshold vector error correction model (TVECM) with regularized Bayesian estimation Technique. The finding provides support for the role of policy intervention in price transmission between import and domestic price.

The subsequent analysis models the spatial market integration in Indonesian beef industry with the multivariate approach. The result draws the dynamics of beef price reaction among the regions that are classified as the main producer and consumer areas in Indonesia. By using Johansen cointegration method and by applying multivariate VECM, this study finds that all of the investigated regions are integrated, implying the existence of 
market integration in Indonesian beef industry.

The third analysis deals with the investigation of price transmission along the supply chain with panel data setting that covers the whole thirty-two provinces in Indonesia. The finding reveals variations in price transmission process among the regions. Finally, the last analysis focuses on the role of regional trade quota policy in beef price formation. Trade quota policy is imposed in some important cattle producer areas, which limits the number of cattle that can be traded out of the regions. This part is analyzed in bivariate setting by constructing trade pairs between producer and consumer areas. Panel data models are employed in assessing the effect of regional trade quota as well as the role of trade cost. The result highlights the effect of trade quota policy on beef price formation. 


\section{Acknowledgments}

I would like to express my gratitude to my supervisor Prof. Dr. Bernhard Brümmer, that I've been given an opportunity to work under his supervision. He always helped me whenever I got a problem or a question about my writing. I can not thank him enough for the time, help, and patience that he gave to me.

I would like to thank Prof. Stephan von-cramon Taubadel for his valuable feedback as a co-referee, and Prof. Matin Qaim as the third examiner.

I must express my very profound gratitude to my family i.e. my parents, my husband, my children, my brothers and sisters, for never ending support and continuous encouragement throughout my years of study and throughout the process of writing this thesis as well.

Finally, I would like to thank all of the people who have made it possible for me to finish this thesis successfully. I am very grateful to my friends and colleagues especially Indonesian friends for their moral and material support during my study.

Author

Anisa Dwi Utami 


\section{Contents}

1 Introduction 1

2 Overview of Beef Industry in Indonesia 3

2.1 Supply Chain of Beef Industry . . . . . . . . . . . . 7

2.2 The Policy Profile in the Indonesian Beef Industry $\ldots . . .8$

3 The Impact of Import Policy on the Domestic Beef Price Formation $\quad 11$

3.1 Introduction . . . . . . . . . . . . . . . 11

3.2 An Overview of Beef Import Policy in Indonesia . . . . . . . . 13

3.3 Methodology . . . . . . . . . . . . . . . 15

3.4 Data . . . . . . . . . . . . . . . 18

3.5 Findings . . . . . . . . . . . . . . . . . 19

3.6 Conclusions .......................... 24

4 Spatial Market Integration Analysis in the Indonesian Beef Industry: A Multivariate Approach 26

4.1 Introduction . . . . . . . . . . . . . . 26

4.2 Methodology . . . . . . . . . . . . . . . 27

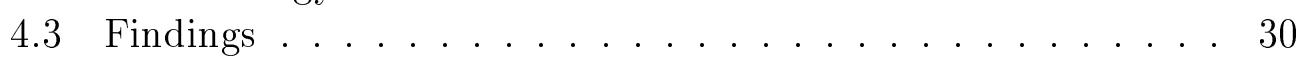

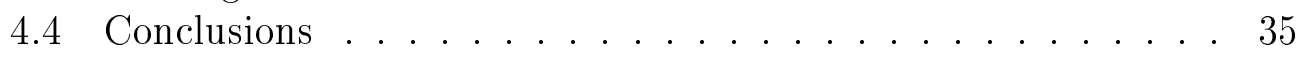

5 Price Transmission along the Supply Chain 39

5.1 Introduction . . . . . . . . . . . . . . . 39

5.2 Data and Methodology . . . . . . . . . . . . 41

5.3 Findings . . . . . . . . . . . . . . . . . . . . . . . . . . . . .

5.4 Conclusions .......................... 49

6 Evaluating the Impact of Regional Trade Quota in Beef Price Formation $\quad 50$

6.1 Introduction . . . . . . . . . . . . . 50 
6.2 Methodology ..................... 51

6.3 Findings . . . . . . . . . . . . . . . . . 52

6.4 Conclusions . . . . . . . . . . . . . . 56

7 Concluding Remarks $\quad 57$

$\begin{array}{ll}\text { Appendix } & \mathbf{6 0}\end{array}$

A Summary Statistics of Retail Beef Prices . . . . . . . . . . 60

B Summary Statistics of Cattle Prices . . . . . . . . . . 62

C The Estimated Speed of Adjustment . . . . . . . . . . 64 


\section{List of Figures}

2.1 Nominal consumer beef price in the main producer regions. . . 4

2.2 Beef production and consumption in Indonesia 2008-2013(Tons) 5

2.3 Cattle Population in Indonesia from 2000-2015. . . . . . . . 6

2.4 Beef Supply Chain in Indonesia. . . . . . . . . . . . . . . 9

3.1 The Monthly Weight of Import Share Value of Beef Products during the estimation period. . . . . . . . . 18

3.2 Price Series used in the estimation in IDR. . . . . . . . . . . 19

3.3 Beef Import during 2002-2015 (tons). . . . . . . . . . . . . . . 22

4.1 Beef Trade Profile of the Selected Markets during 2006-2015. . 32

4.2 Forecast variance error decomposition. . . . . . . . . 36

5.1 The Estimated Speed of Adjustments by PMG estimator. . . 48

6.1 Regional Export-Import of Cattle for Some Producer Areas during 2008-2015. . . . . . . . . . . . . 5 5 


\section{List of Tables}

3.1 The Results of the $A D F$ Unit Root Tests Price Variable Level First Difference. . . . . . . . . . . . . . 20

3.2 The Results of the Johansen Cointegration Test and Seo's Threshold Cointegration Test. . . . . . . . . . 20

3.3 The Results of the Long Run Estimation. . . . . . . . . . . . 21

3.4 The Results of the TVECM Estimation using the Regularized Bayesian Technique. . . . . . . . . . . . 23

4.1 Summary Statistics for The Investigated Price Variables in IDR. 28

4.2 The Results of Unit Root Tests by ADF Test. . . . . . . . . . 30

4.3 The results of Johansen Cointegration Test. . . . . . . . . 31

4.4 Normalized Cointegrating Vector by Johansen Method. . . . . 33

4.5 Adjustment Coefficients from the Restricted $V E C M$. . . . . . 33

4.6 The Estimated Half-Life Time (months) from the VECM. . . 35

4.7 Forecast Variance Error Decomposition for JKT. . . . . . . . . 37

5.1 Summary Statistics of Variables. . . . . . . . . . . . . . . 41

5.2 The Results of Panel Unit Root Tests. . . . . . . . . . . . . 45

5.3 The Results of Westerlund Panel Cointegration Tests. . . . . . 46

5.4 The Results of Long-Run Estimation by PMG Estimator. . . 47

5.5 Summary descriptive of the Estimated Speed of Adjustments. 49

6.1 The Results of Panel Regression Models. . . . . . . . . . . 53 


\section{Chapter 1}

\section{Introduction}

Food price is one of the major interests in the economy as many poor people spend half of their household income on food. As price guides how production and consumption will be determined, the understanding of price determination is, therefore, necessary particularly in the food sector of developing countries. Along with the complication analysis in economic theory, there are multiple factors that determine price dynamics. For agricultural commodities, with their special characteristics, government intervention highlights the market profile in many countries. Generally speaking, governmental regulation and intervention are attempted to reach better welfare for the entire economy. However, it is not as easy as assumed in the theory. Therefore, assessing the effect of policy intervention on price formation is inevitable.

This study aims to provide empirical evidence on how governmental policy intervention plays role in price formation in the context of Indonesian beef industry. Being one of the most important food products in Indonesia, beef consumption level tends to increase from time to time, along with the changing socioeconomic condition. As a response to this situation, the Indonesian government has attempted to reach self-sufficiency, which is declared in the so-called Beef self-sufficiency road map policy 2010-2014 (BSSP 2010-2014). The beef self-sufficiency policy (BSSP) targets to fulfill $90 \%$ of domestic demand through domestic production. By reducing import and improving productivity at the same time, the government aims to fulfill domestic demand and to increase farmer's welfare. However, this policy triggers debate on whether it will create higher price volatility, particularly in the short run, and whether the local farmers who are dominated by smallholders will get a better price after the government imposes the restricted import policy. 
Representing one of the essential food products, the beef market has been subjected to numerous interventions by the government. With regard to beef self-sufficiency orientation, it is interesting to see how beef price responds to the policy. The question then moves to how does the policy affect market integration in Indonesian beef industry, and to how are market changes, which refer to price changes, transferred to the local beef farmer? The analysis on how prices are transmitted from one chain to another can imply how price determination processes in the supply chain are. The evaluation of such self-sufficiency policy with concern on price performance, particularly that involves the whole supply chain, is rarely studied in Indonesia.

This thesis consists of six chapters, starting with an introduction that delivers the motivation of the study. The second chapter provides an overview of the industry profile, involving the explanation about supply chain and related policies during the investigated periods i.e. 2002-2015. Subsequently, it continues with four main analysis in the study. The first analysis is about the impact of import policy on price transmission between domestic and import prices; the second is spatial market integration analysis; third is price transmission analysis along the supply chain; and the last analysis assesses the role of regional trade quota in price formation. Finally, conclusion and policy implications are discussed at the end of this thesis. 


\section{Chapter 2}

\section{Overview of Beef Industry in Indonesia}

Beef is one the most important food products in Indonesia. The consumption tends to increase as socioeconomic condition changes. There are several main driving factors that are responsible for the growing demand for beef in Indonesia: consistent annual population growth (1.49\% in average per year) and improvement in the real income per capita (12.49\% in average per year). In comparison with other animal food products, beef is generally considered by Indonesian society as luxury food that is relatively more expensive than other food products like, for instance, poultry and fish. However, in spite of the price, some consumers are still willing to buy it due to its unique taste. This luxury image, as well as consumers' preference on taste, have significantly promoted the growth of beef processing industry. Finally, successful expansion of tourism industry (i.e. hotels and restaurant), despite the varied consumption patterns across regions, has also contributed to positively shifting the beef demand. All of these factors have significantly promoted the growth of beef processing industry. There are several differences in the consumption pattern of the region. As shown in Figure 2.1, the beef price is consistently increasing over years. 
Figure 2.1: Nominal consumer beef price in the main producer regions.

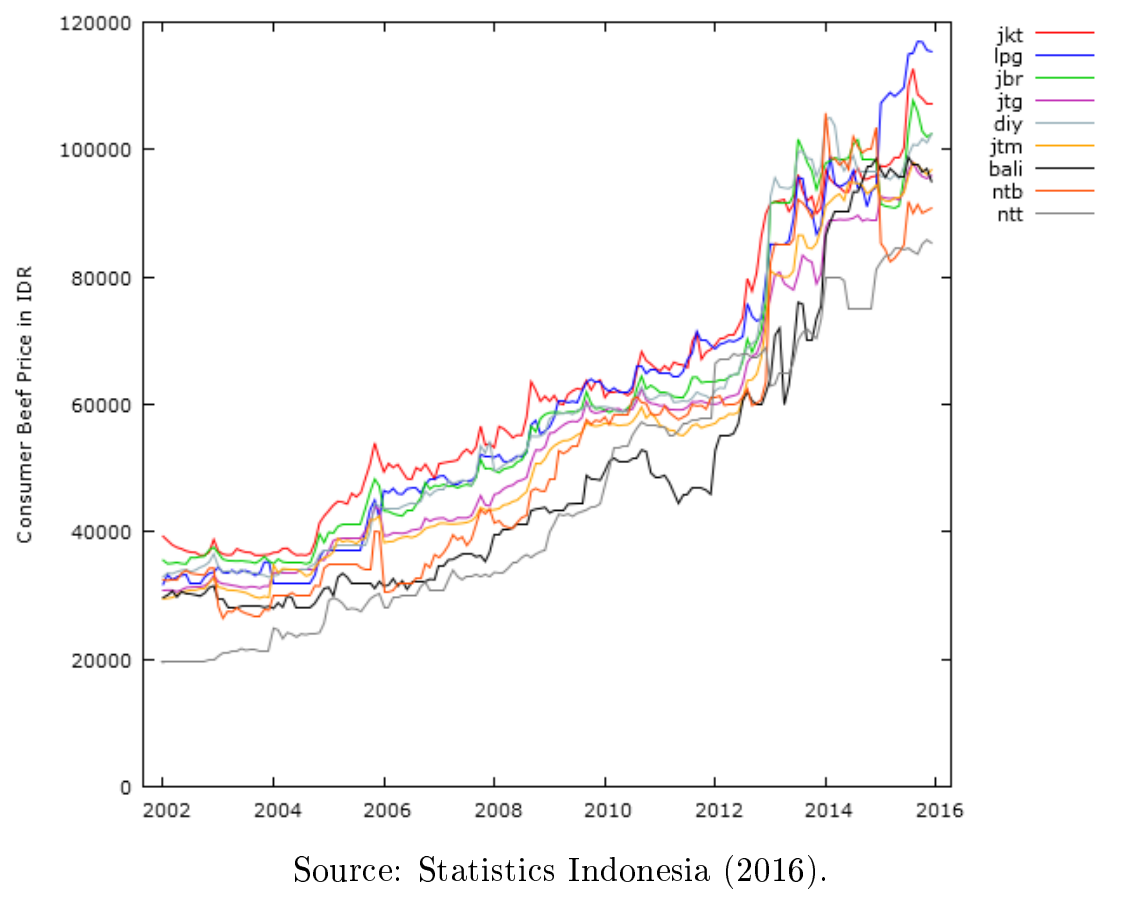

In response to high domestic demand of beef, the Indonesian government tried to introduce beef self-sufficiency program (BSSP) in 2010 that aimed at fulfilling the domestic demand by ninety per cent from domestic production. According to the BSSP Road Map published by Indonesian Ministry of Agriculture (2010), beef-import-restriction policy was imposed at nearly fifty per cent annually between 2010 and 2014 . However, the data issued by the Indonesian Statistics shows that the supply side was growing slower than the actual demand, as seen in Figure 2.2. 
Figure 2.2: Beef production and consumption in Indonesia 2008-2013(Tons)

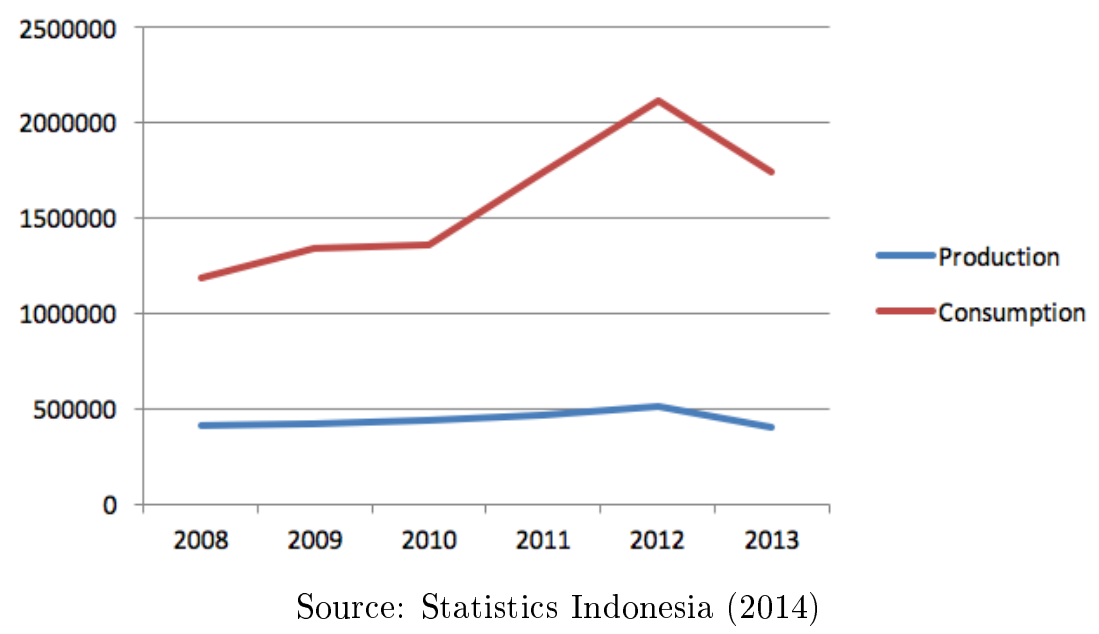

During 2000-2015, as shown in Figure 2.3, the number of domestic beef production was quite fluctuating from 2003 to 2009 but consistently increasing since 2010 with $9.1 \%$ annual growth rate as a direct effect of the beef self-sufficiency program enforced during the period. Similar to the domestic beef production pattern, beef cattle population has also been increasing overtime i.e. $8 \%$ on average per year. However, a dramatic decrease happened in 2012. Beef import restriction imposed in 2012 and 2013 had led to a massive cattle slaughtering as a response to the high beef demand. Nearly 3.3 million heads were slaughtered during this single period.

The supply of domestic beef is mainly coming from two main sources: local beef cattle (it includes dairy cattle and culled dairy cows) and imported cattle feeders (feeder steer), that are fattened in Indonesia for about 100 days. Most of the cattle feeders are imported from Australia. As a common fact in developing countries, Indonesian beef industry is also dominated by smallholder farmers. According to the latest government survey conducted in 2013, the average number of cattle owned per Figure 2.3 is only around three animals. The highest cattle population is located in Java Island, which represents $50.68 \%$ of the total cattle population in Indonesia (Statistics Indonesia, 2013), while the rests of the population are situated outside Java, including Sumatera (18.38\%), Bali and Nusa Tenggara (14.18\%), Sulawesi (12.08\%), Kalimantan (2.95\%), and Maluku 
and Papua (1.75\%). Among these islands, at the provincial level, there are five main producer areas that supply the whole demand for beef cattle in Indonesia, i.e. East Java, Central Java, Bali, West Nusa Tenggara, and East Nusa Tenggara.

Figure 2.3: Cattle Population in Indonesia from 2000-2015.

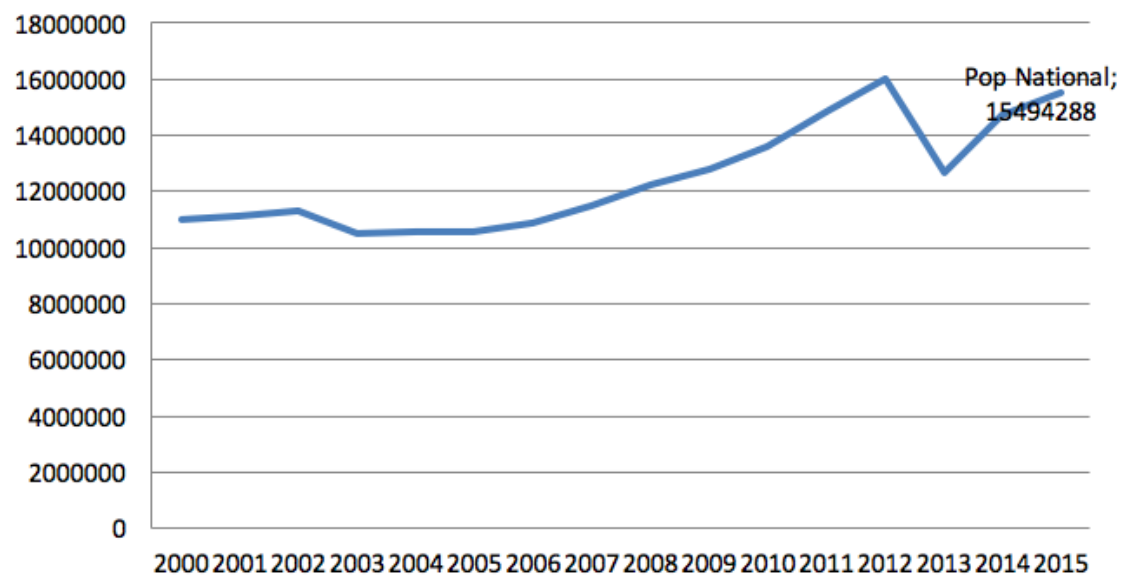

Source: Statistics Indonesia (2015)

Different from other countries, Indonesian cattle is not always bred in grassland. In Java Island, for instance, where the main production areas are located, there is absolutely no pasture. Field grazing is only found in Nusa Tenggara production area.In general, there are three development patterns of beef cattle in Indonesia.First, a development associated with agricultural cultivation. This type of pattern is mainly developed in JavaIsland. Second, a development pattern that is not related to agriculture suitable for areas characterized by less fertile land, hard water, high temperatures, and less populated, such as in Nusa Tenggara. Finally, the third pattern requires high capital and is usually conducted in large scale. In addition, it is important to note that most companies applying the third pattern import their feeder cattle from abroad.

There are several problems that arise at the supply side, which generally result in the lack of productivity. According to a study conducted by Bappenas in 2013, there are three responsible factors that underlie the slow growth of beef cattle population in Indonesia. First, in most cases, 
particularly in Java Island, cattle is considered as a household asset, not for business purposes. Thus, the farmers will sell their cattle whenever they need fresh money without considering its long-term profitability. Second, massive construction for the residential purpose has significantly reduced the availability of grassland, especially in the eastern part of Indonesia, such as Nusa Tenggara. Third, government's inability to control the slaughtering of productive beef cattle has consequently led to the decrease of newborn calves figure.

\subsection{Supply Chain of Beef Industry}

The trade flow of Indonesian beef Industry, from live cattle to beef at end consumers, is captured in Figure 2.4. As depicted, instead of selling beef directly from the producer areas to the consumer areas, due to unsupportive infrastructure, lack of modern trading facilities, and geographical challenges, live cattle is traded across the regions. Therefore, cattle is commonly slaughtered in consumer areas. Moreover, beef trading activities between regions on the same island or within the neighboring areas are usually conducted by private companies with vertical integration of their business.

It is also important to note that there many intermediaries along the supply chain, from village level, regional level, to intra-regional level. Before transported to other regions, the transaction of live cattle is usually conducted in a special market called 'animal market' (pasar hewan). Each animal market across the regions implements a distinct operational procedure, which differentiates them from one another. However, in general, most animal markets operate once a week on a particular day. According to a survey conducted by the Ministry of Agriculture (2013), there are five main actors that continuously engage in trading activities within animal markets, including slaughter men, or also known as jagal (representing nearly fifty percent of the trader population), district traders (twenty percent), village traders, intra-regional traders, and brokers (around ten percent respectively). Concerning the payment method, transactions in animal market can be done not only by cash payment but also by debt or deposit.

Live cattle is also traded across islands to the meet beef request from other regions outside the island. Inter-island trade is considered unique in 
comparison with intra-island trade with respect to transportation and marketing system. There are several kinds of transportation modes used in inter-island trade, including, among others, special charter system for cattle, which is commonly used for inter-island trading from East Java to Kalimantan and from NTB or NTT to Sulawesi and Papua. This transportation mode is relatively expensive but more flexible in schedule. The average capacity of this special charter system is around 300 to 500 cattle for every loading. There is also the so-called one-way freights, which is widely used to support trading activities to Jakarta and Sulawesi. With this system, the cost is cheaper than the previous system, but it is stricter in the schedule and only allows smaller number of cattle per loading. The third mode is one-way ferry (kapal roro) that is commonly used to transport live cattle to Sumatera. Considering the high transportation cost in inter-island trade, there are some problems that may contribute to the creation of market inefficiency. The traders often have to bear some loses due to, for instance, cattle weight loss during the freight as a result of an inadequate facility on board. Moreover, it is even more challenging for traders because of the absence of insurance in this sector to cover potential losses. Finally, the traders are also often being the subjects of some illegal charges during the trip.

Generally, there are five elements that compose the overall trade cost of live cattle in the Indonesian beef industry: transportation cost; labor cost to protect the cattle during the shipment; retribution or special tariff commonly charged by the regional government that varies across the regions, such as retribution for health-checking, rent fee for abattoir facility, post-mortem check, and recommendation letter to distribute meat or cattle in and out of the region; feeding cost during the trip; and depreciation costs following potential cattle weight loses during shipment. Based on an interview with a trader, the common depreciation rate is approximately ten percent of intraisland trade, and twelve percent for inter-island trade.

\subsection{The Policy Profile in the Indonesian Beef Industry}

In terms of government intervention on beef market, there are several types of policy imposed at both national and regional level. The policies at national level mainly deal with import restriction issues. As mentioned earlier, since 2010, Indonesian government has been attempting to achieve 


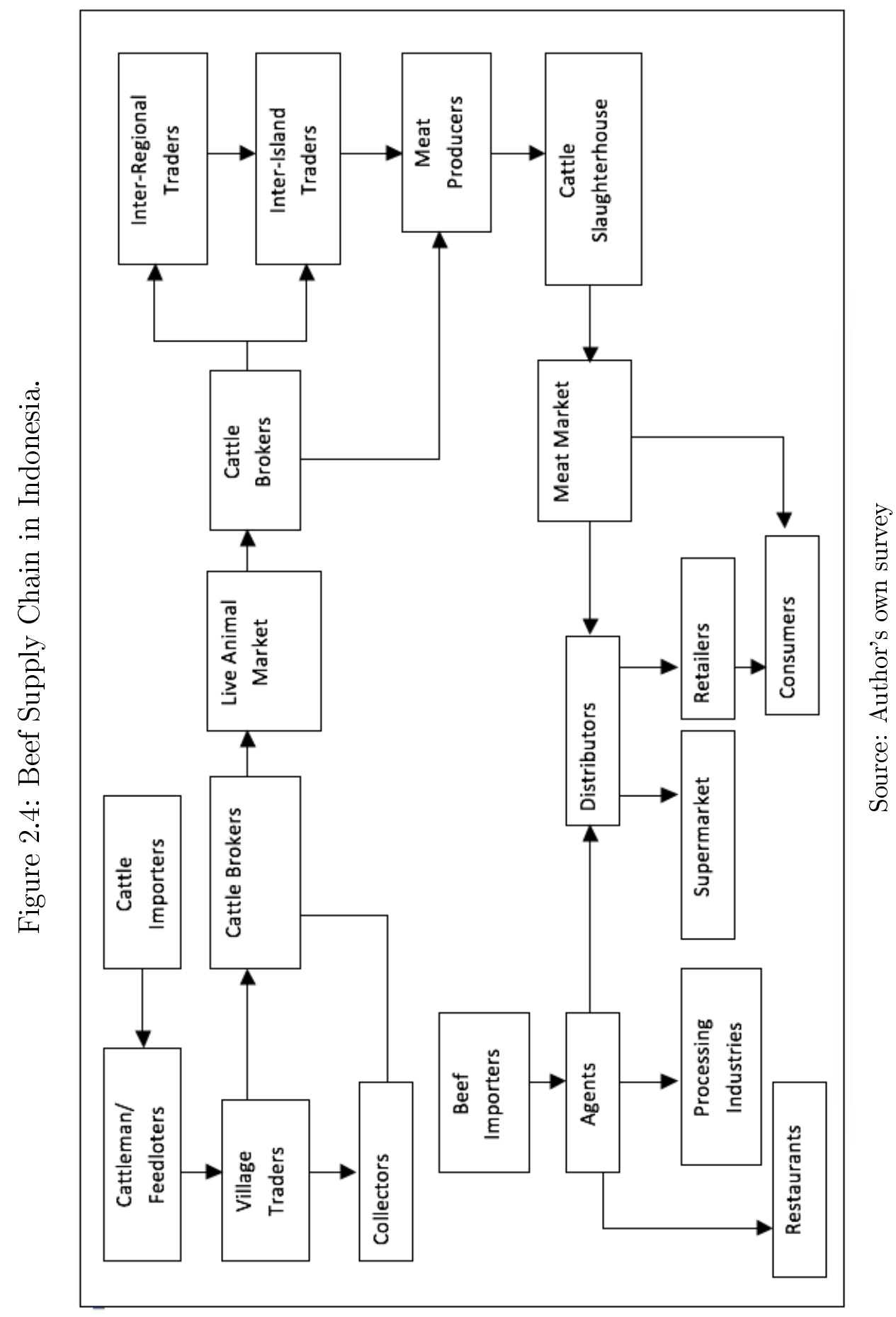


self-sufficiency status in beef sector. With this framework, Indonesia has once tried to dramatically reduce import volume to merely ten per cent level from the overall domestic consumption. Henceforth, Indonesia's import-related policy has been changed several times from time to time.

The government imposes import tariff and quota for beef products and live cattle. Due to the self-sufficiency policy, during the 2010-2014 periods, frozen beef and live cattle imports were restricted by the import quota policy. In order to maintain livestock supply, the government prohibited the slaughtering of productive cows. Most of feed regulations particularly focus on technical and safety requirements. However, regulations on many imported products are not listed specifically on the law manuscript. The government charges five percent import tariff to biological medicines, and plus ten percent value added tax to pharmaceutical medicines and premix. In contrast to the previous policy, in 2013, as notified by the decree of the Minister of Trade No.699/MDAG/KEP/7/2013, import restriction was replaced by price preference policy. According to this policy, import will be permitted if the beef price in traditional market has reached fifteen percent above the preferred price, which is equal to IDR 76.000 per $\mathrm{kg}$.

At regional level, some producer areas have imposed trade quota policy, which limits the number of live cattle that can be traded out of the regions. Generally, the quota would be imposed depending on the prediction of cattle population's growth rate and beef consumption rate at a particular period of time. If the growth rate of cattle population is lower than the consumption rate, then the government would apply the quota. The government argues that such quota policy is applied in order to prioritize the local demand of beef as a response of the high demand of live cattle from other regions. 


\section{Chapter 3}

\section{The Impact of Import Policy on the Domestic Beef Price Formation}

\subsection{Introduction}

In a globalized economy, there are multiple possibilities for countries to meet their domestic needs with national as well as international products. Due to its growing worldwide importance, trade's impact on the economy, particularly on import related issues, have been widely discussed. Products are usually imported to fill an existing gap between production and consumption. According to the economic theory, there are several reasons why a country imports a certain product from an international market like e. g., lacking resources for domestic production, or price related issues. However, decisions on whether to import often involve further discussions about consumer benefits and potential damage to local producers. Therefore, some governments implement restricted import policies, particularly for food products since those can have serious implications for the welfare of small farmers.

The rise of middle-class income as a particular impact on growing economies has led to a change in consumption patterns. Such an economic profile has been commonly found across numerous emerging countries. Indonesia, as one of the southeast Asia's biggest countries, is not an exception. For many years, Indonesia has been a large net importer for a number of important food products. Most of the Indonesian major food staples such as rice, maize, cassava, soybean, and sugar, are all imported 
(Statistics Indonesia, 2015). This profile is also captured within the beef industry. As one of the most important food products, consumption of beef among Indonesians has shown an upward trend during the last decades. It can be predicted that this situation is likely to continue in the future, as the people consume more beef than other meat products. However, the increasing trend in consumption has not been followed by an equal trend on the supply side. There are still some problems in the beef production sector hindering productivity improvement including, among others, lack of resources, and low of technology issues.

Being an importing country for important food products, Indonesia has maintained a number of protectionist trade policies. Indonesia is an active member of G20, APEC, and ASEAN, which promote integration with other countries and liberalization, but on the other hand, the Indonesian government still maintains protectionist policies. Protectionism carried out through import restrictions, particularly for some major food products. In fact, high domestic demand, as a direct implication of population growth, has encouraged the government to pursue self-sufficiency to ensure food security. However, the inability to provide the required food products from domestic production has been the main inhibiting factor for the self-sufficiency ambition. This complex situation leaves the government with no other choice than to import from other countries while maintaining restrictive import policy. During the last decades, there were some policy changes regarding the beef industry, particularly with respect to import regulations. After claiming the beef self sufficiency objective in 2010, import restrictions in the industry profile were highlighted by a reduction of import quota. Accordingly, since the domestic beef price tends to increase overtime, the government reacted to this situation by moving to the price reference policy in 2013. Other changes were implemented regarding import procedure and related technical requirements.

For the government, stabilizing prices requires a thorough understanding of the main factors affecting market behavior, including price spillover between markets. With market integration as a framework, this chapter aims to analyze the impact of import policy on the domestic beef price formation in Indonesia. Previous studies have investigated market integration in the livestock sector, for example, Bizimana et al (2015) examined cattle markets in Mali, Ihle et al (2012) analyzed the European calf market, and Vollrath (2006) the US-Canadian meat market. Meanwhile, a growing number of studies on price transmission in 
agricultural markets assesses policy intervention, like, for example, Jamora (2016) for international rice markets, Götz et al (2013) for Ukranian and Rusian wheat market, and Bolotova and Novakovic (2011) on the US milk market. In most of the aforementioned literature, the role of policy intervention is analyzed by referring to periods stages of introducing this policy and its effects. Unlike the usual approach commonly used in the existing literature, the policy effect is investigated explicitly through the price transmission process between domestic price and import price.

Empirical investigation is conducted using the threshold vector error correction model $(T V E C M)$ with regularized Bayesian estimation Technique developed by Greb et al (2011). TVECM gained popularity following Balke and Fomby's (1997) article on threshold cointegration. Accordingly, Goodwin and Piggott's (2001) seminal paper applied TVECM for price transmission analysis, as well as a number of studies on agricultural markets, e.g. Valdez (2015), Jamora (2016), Greb et al (2013), Abidoye (2014), and Falsafian (2008). With the use of TVECM the problem of excluding transaction costs while analyzing price transmission can be solved. Testing market integration with regression-based tests without accounting for transaction costs may result in misleading inference (Goodwin and Piggott, 2001; Meyer and Von Cramon-Taubadel, 2004). In such models, the estimated thresholds can be interpreted as the transactions cost. The regularized Bayesian technique, on the other hand, is an improved technique for estimating thresholds in the TVECM, which can tackle the bias that commonly arises in the use of profile likelihood estimation technique.

The next section provides an overview of import policies in the Indonesian beef industry during the periods of 2002-2015. Subsequently, sections three and four explain methodology and data resources, findings are discussed in section five, and the last section closes with the conclusion.

\subsection{An Overview of Beef Import Policy in Indonesia}

Representing one of the essential food products, the beef market has been subject to numerous interventions by the government, primarily with regard to import regulations, with the primary goals of protecting local producers and consumers, achieving self-sufficiency, improving industry 
competitiveness, and price stabilization. Besides fulfilling the demand, importing activities also used by the government as a tool to stabilize the beef price by conducting market operation using imported products. Such actions are commonly implemented during seasons of high demand, such as Ramadan and other Islamic holidays, when prices increase dramatically.

Indonesian government imposes import tariffs and quota for beef products and live cattle. Due to the self-sufficiency policy, between 2010 and 2014 frozen beef and live cattle import were restricted by the import quota policy. As part of the government's attempts to reach self-sufficiency status in the beef sector, the import volume was dramatically reduced by allowing the imported products to fulfill only ten percent of the overall domestic consumption. A five-percent import tariff for beef and edible offal, and null percent for breeding and feeder cattle have been applied since 1999. There is also a null percent entrance fee for imported feeder cattle. According to the regulations, the imported feeder cattle's live weight must not exceed $350 \mathrm{~kg}$, its age is not to be higher than thirty months, and it has to have spent at least sixty days of fattening in feedlots. The quota for imported cattle for individual feedlots depend on its holding capacity and other requirements. Additionally, feedlots have to purchase a minimum of ten percent of feeder cattle from domestic producers in order to be granted a higher import quota from the government. Most feeding regulations are particularly related to technical and safety requirements, however, it is important to note that regulations on many imported products are not specifically listed on the law manuscript. The government imposes a five percent import tariff on biological medicines and a ten percent value added tax on pharmaceutical medicines and premixes.

On August 2013, Indonesian government through the Ministry of Agriculture (MOA) and the Ministry of Trade (MOT) released several new regulations on meat and meat products imports. In comparison to the previous regulation, one of the primary features of the new regulations is the implementation of price reference system. According to the regulation, the government will not issue the import permit if local meat price is below the predetermined price i.e. IDR $76.000 / \mathrm{kg}$. This reference price is set and monitored by the MOT. Furthermore, there are no more special provisions for prime cuts both fresh/chilled and frozen. Unlike before, the import volume will be determined by the MOT through Import Approvals (SPI), and no longer by the MOA. An import permit requires a recommendation on Technical Veterinary Public Health signed by the Directorate of Veterinary and Public Health and Post Harvest from the MOA, making a 
recommendation from MOA directors general of Livestock and Animal Health unnecessary. Generally, imports can be conducted by business corporations, social institutions, foreign country representatives, international institutions, and government- or state-owned companies. However, following regulations, each of the aforementioned institutions have to meet different sets of criteria and distinct import specifications. Business corporations, for instance, have to own cold storages and refrigerated transportation and are only allowed to distribute imported meat to industries, hotels, and restaurants, whereas state-owned companies have permission to market imported meat to food retail for market operation.

Following the price reference policy, as a response of increasing domestic prices, the government appointed the National Logistic Agency (BULOG) to conduct beef importation and its subsequent distribution to the retail market. This appointment was initially aimed at stabilizing the beef price. However, it currently concentrates on filling the beef stocks in Jakarta and West Java. During 2013, BULOG was permitted to import three thousand tons of beef with price ranging from IDR 70,000 to 80,000 per kilogram (Permana, 2013). However, this strategy was found ineffective as it was unable to maintain price stabilization. Therefore, based on the ministerial decree of the MOT No. 57/M-DAG/PER/8/2013 published on 26 September 2015, the BULOG's roles regarding the importation and retail distribution of beef were then eliminated.

\subsection{Methodology}

As applied in most of the existing literature, the starting point for modeling spatial market integration is taken from the notion of a spatial arbitrage condition and the law of one price (LOP). The spatial arbitrage condition holds when the price of homogeneous products at any two locations does not exceed the cost of delivering the product from a region with a lower price to a region with a higher price:

$$
p_{j}-p_{i} \leq r_{i j}
$$

where $r_{i j}$ represents the cost of moving the product from location $i$ to $j$, including costs for transportation and for arranging transactions among spatially separated markets (Fackler and Goodwin, 2001). It is important to understand that the notion of spatial arbitrage is an equilibrium concept. This means that in a well-functioning market, though the actual price may 
diverge from this relationship 3.1, the action of arbitrageurs helps to move the price spread to the actual trade cost $\left(r_{i j}\right)$.

Literature offers several approaches to assess the existence of market integration. The most popular approach is the time series technique which focuses on the co-movement of price series, such as co-integration analysis, error correction model, and granger causality, to measure the degree of market integration. The estimation relies on the equation which explains that price in one location is a function of current and lagged prices in another location i.e.

$$
P_{j t}=\beta_{0}+\sum \beta_{1} P_{k(t-T)}+\epsilon_{t},
$$

where $P_{j t}\left(P_{k t}\right)$ is the price in market $k_{(j)}$ at time $t$ and $\epsilon$ is a random error. Then the market integration is indicated by the sum of the coefficient of prices which should be equal to 1 for the perfect integration. However, the process of spatial price transmission can be nonlinear which is generally assumed to be regime dependent.

The Threshold Vector Error Correction Model (TVECM) is commonly used for assessing this behavior of regime-dependency suitable for the spatial price transmission process. Following the assumption of a non-linear relationship in the price transmission process between the domestic price and import price, we apply the $T V E C M$ with two regimes and one threshold as can be represented:

$$
\Delta p_{t}= \begin{cases}\alpha_{1}\left(z_{t-1}-\tau\right)+\sum_{j=1}^{k} \beta_{1, j} \Delta p_{t-j}+\epsilon_{1, t} & \text { if } z_{t-1} \leq \tau \text { Regime } 1 \\ \alpha_{2}\left(z_{t-1}-\tau\right)+\sum_{j=1}^{k} \beta_{2, j} \Delta p_{t-j}+\epsilon_{2, t} & \text { if } z_{t-1}>\tau \text { Regime } 2\end{cases}
$$

where $p$ represents prices. While the parameters to be estimated are $\alpha$ which are the so called the speed of adjustments, $\tau$ represents the threshold.

In order to capture the dynamics in the Indonesian beef industry during the estimation period while taking into account policy changes, the long run equation was modified by imposing dummy variables representing the different policies, as represented:

$$
\ln P_{d}=\beta_{0}+\beta_{1} \ln M+\beta_{2} D_{1}+\beta_{3} D_{2}+\beta_{4} D_{3}+\epsilon_{t},
$$

where $P_{d}$ represents domestic price, $M$ denotes the import price, and $D_{1}$, $D_{2}, D_{3}$ are the dummy variables presenting the respective policy. $D_{1}$ accounts for the periods before the beef self-sufficiency policy (BSSP) from 
January 2002 until January 2010, $D_{2}$ stands for the periods of an active BSSP from February 2010 until July 2013, and $D_{3}$ presents the price reference policy which was applicable from August 2013 until December 2015 .

The estimation of TVECM is typically performed using profile likelihood estimator as introduced by Hansen and Seo (2002) which is referred as a grid search technique. With this technique, every possible value for a threshold is estimated separately. The pair of the threshold parameters, which maximizes the profile likelihood function, is selected as the best-fitted results (details can be seen in Greb, 2013). However, as demonstrated by Greb and colleagues (2013, 2014), this profile likelihood technique produces some bias and tends to have a high variance. One of its key problems is that this technique requires a high number of observations to achieve a sufficient degree of freedom in estimating the parameters. In its practical implementation, this technique is connected to a setting of an arbitrary trimming parameter that determines the minimum number of observations to be included in the grid search. The risk of a bias can especially occur with a small sample that excludes the true threshold from the grid search. Theoretically, this problem is likely to appear in efficient markets with little arbitrage actions, leading to fewer observations in the outer regime.

Therefore, considering the shortcomings of profile likelihood estimation technique, we applied the Regularized Bayesian Estimation Technique $(R B E)$ in estimating the TVECM as introduced by Greb, et al. (2011, 2013). The main feature of this technique is a data-driven regularization that penalizes the difference between regimes to keep these differences as small as possible, even if the data contains only little-information. As a consequence, a posterior density is well-defined on the entire threshold parameter space, thus the requirement for trimming parameters is eliminated and the risk of excluding the true thresholds from the estimation is reduced.

In brief, our estimation steps are summarized as follows. First, we checked for the time-series properties of the data using Augmented Dickey Fuller unit root test. Second, we applied Johansen cointegration test as well as the significance of thresholds effects using Seo's Sup wald Test (2006). Finally, we estimated the thresholds and TVECMs using RBE developed by Greb et al (2013). The lags selection in the $T V E C M$ is based on Akaike Information Criteria $(A I C)$. 


\subsection{Data}

We analyzed monthly series data covering periods from 2002 until 2015, resulting in 168 observations, provided by Statistics Indonesia. In order to capture the research question on the effect of import on domestic price dynamics for the Indonesian beef industry, we constructed an import price by averaging the weighted arithmetic mean from ten imported beef products, (referred to $H S$ codes), and defined as follows:

$$
M=\frac{\sum_{i=1}^{n} w X_{i}}{\sum_{i=1}^{n} w}
$$

where $X_{i}$ represents the import price and w represents the weight as the import share value of the respective beef product. In this application, as shown in the figure, we used the value for annual weight, since the weight shows annual structural patterns during the periods of estimation. For the domestic price, we used monthly beef consumer price data from Jakarta and West Java provinces. We chose them because imported beef products are mainly entering through these regions. Furthermore, all price variables were transformed into logarithmic form.

Figure 3.1: The Monthly Weight of Import Share Value of Beef Products during the estimation period.

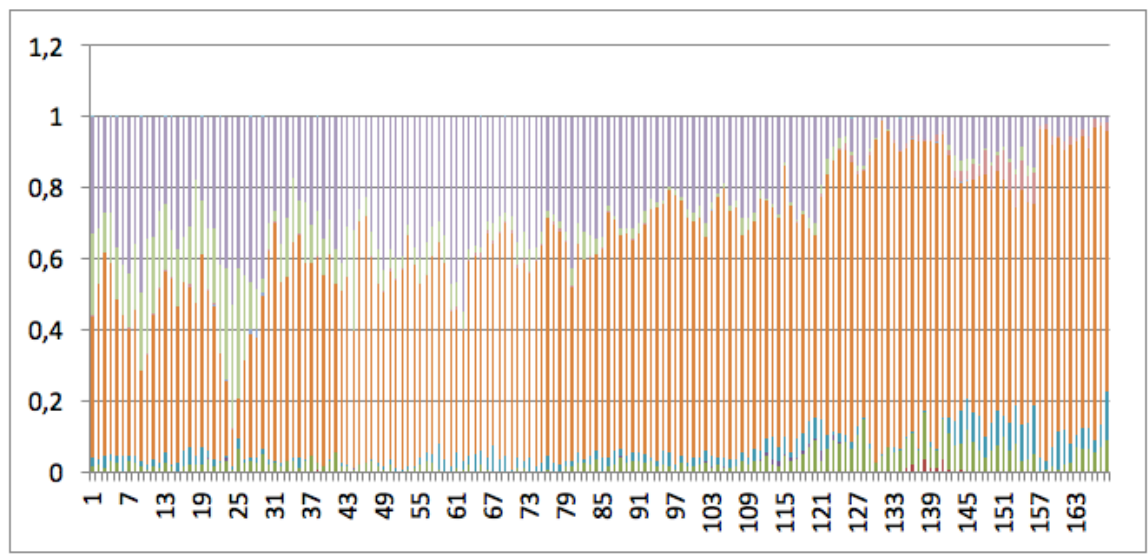

Notes: Colors represent for a particular beef product refer to $H S$ codes 
Figure 3.2: Price Series used in the estimation in IDR.

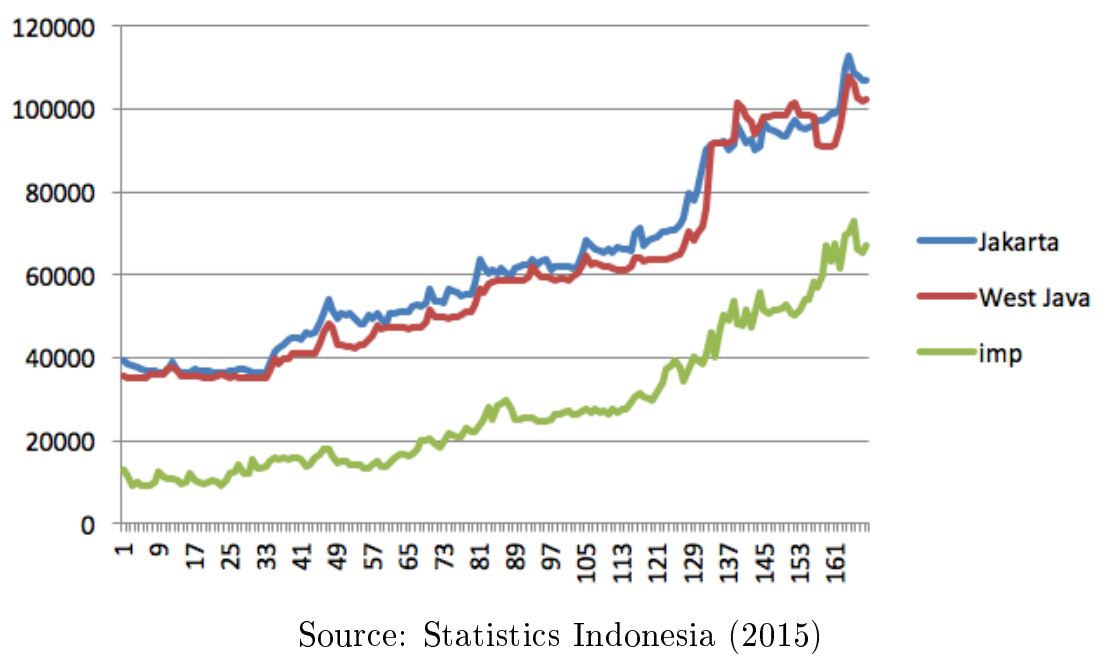

\subsection{Findings}

The results of the $A D F$ unit root test as presented in the table below show the price series for all investigated variables to be stationary at the first difference, i. e., I(1). After finding that all price variables have the same order of integration, as mentioned before, we then conducted cointegration tests by using the Johansen cointegration test, and we tested for the significance of threshold effects by using the Seo Sup Wald-Test (2006) for threshold with 1000 replications in parameter bootstrapping. As shown in the table, both tests are suggesting the existence of cointegration relationships between the import beef price and the beef domestic price as well as the thresholds effect.

The results of the long run estimation showed a price elasticity of the import price at $48 \%$ for Jakarta and at $43 \%$ for the West Java market. This leads to the interpretation that a $1 \%$ increase in import prices averagely result in a $48 \%$ price increase in Jakarta and a $43 \%$ price increase in West Java respectively, ceteris paribus. These findings seem to be plausible regarding the position of Indonesia in the world market as a net importer in the beef industry. Even though the Indonesian government aims to become self-sufficient in the beef industry, this suggests the dependence of Indonesia to the world market for fulfilling the domestic demand. 
Table 3.1: The Results of the $A D F$ Unit Root Tests Price Variable Level First Difference.

\begin{tabular}{|c|c|c|}
\hline Price Variable & Level & First Difference \\
\hline \hline Jakarta & 0.2301 & $-11.560^{* * *}$ \\
\hline West Java & -0.1660 & $-10.209^{* * *}$ \\
\hline Import & -0.0987 & $-11.632^{* * *}$ \\
\hline
\end{tabular}

Notes: *** statistically significant at $1 \%$ level. The null hypothesis is that price series contain the unit root.

Table 3.2: The Results of the Johansen Cointegration Test and Seo's Threshold Cointegration Test.

\begin{tabular}{|c|c|c|}
\hline Cointegration Relations & $\begin{array}{c}\text { Johansen } \\
\text { Cointegration Test }\end{array}$ & $\begin{array}{c}\text { Seo's Threshold } \\
\text { Cointegration Test }\end{array}$ \\
\hline \hline Jakarta-import price & 0.000 & 0.000 \\
\hline West Java-import price & 0.000 & 0.000 \\
\hline
\end{tabular}

Notes: numbers are the p-values. The null hypothesis is no-cointegration. 
Table 3.3: The Results of the Long Run Estimation.

\begin{tabular}{|c|c|c|}
\hline The Estimated Variables & Jakarta & West Java \\
\hline \hline Import price & $0.484(0.027)^{* * *}$ & $0.429(0.028)^{* * *}$ \\
\hline$D_{1}$ & $0.062(0.020)^{* *}$ & $0.086(0.021)^{* * *}$ \\
\hline$D_{2}$ & $0.096(0.029)^{* *}$ & $0.145(0.029)^{* * *}$ \\
\hline$D_{3}$ & $0.138(0.043)^{* *}$ & $0.288(0.045)^{* * *}$ \\
\hline Intercept & $6.050(0.258)^{* * *}$ & $6.503(0.266)^{* * *}$ \\
\hline Adjusted $R^{2}$ & 0.9614 & 0.9629 \\
\hline
\end{tabular}

Notes: number in parentheses represents the estimated standard error, $* *$ Statistically significant at $5 \%, * * *$ Statistically significant at $1 \%$.

As discussed earlier, the Indonesian beef market has been highly intervened by government policies. In order to capture this effect, we modified the dummy variables (i. e. $D_{1}, D_{2}$, and $D_{3}$ ) in the long run estimation to represent the different regulations. As expected, all of the dummy variables are statistically significant for both the Jakarta and West Java markets. Analyzing the magnitude of the estimated coefficient, both Jakarta and West Java have shown similar patterns. The effects of the implemented import policies are gradually increasing during our investigated periods. Even though Indonesian government targets to limit the import dramatically as mentioned explicitly in the self-sufficiency policy in the beginning of 2010, but as depicted in the figure, the import was still existed and even increasing compared to that in the previous periods. However, the import restrictions were seen during 2011-2013, but then the import was surging in 2014. 
Figure 3.3: Beef Import during 2002-2015 (tons).

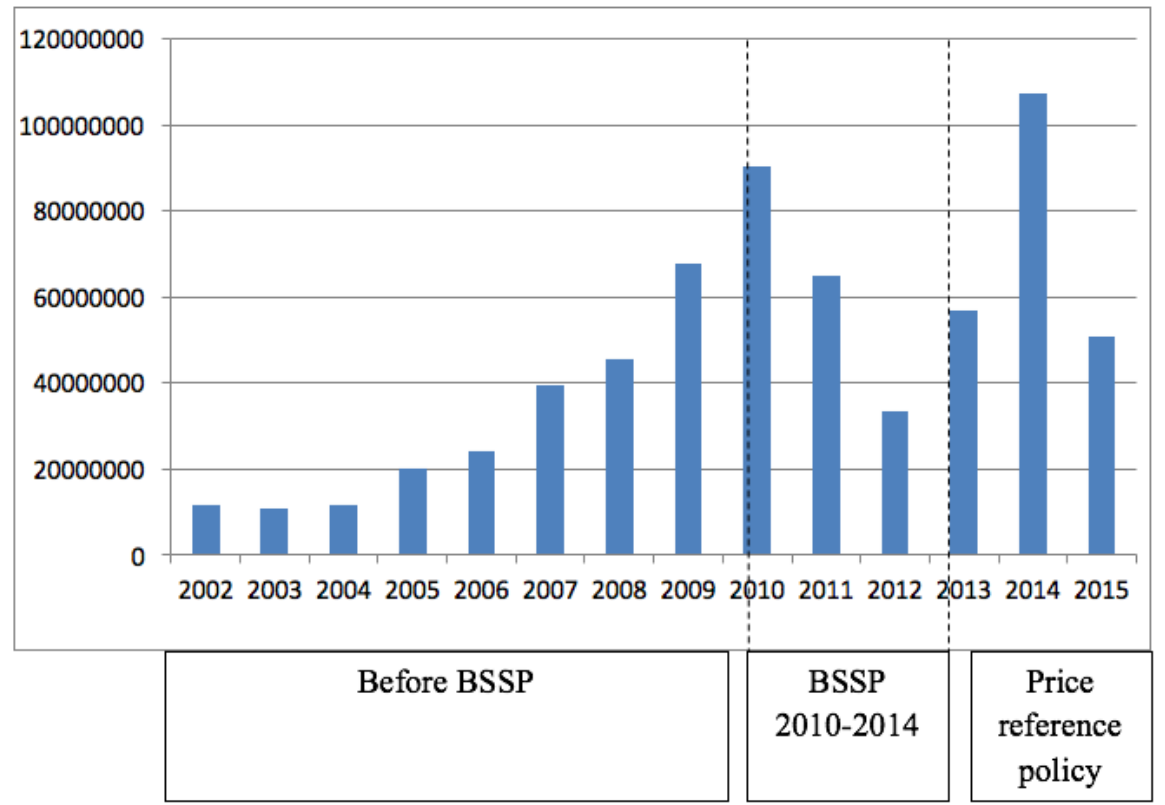

Source: Statistics Indonesia (2015)

If we compare the estimated coefficients of $D_{2}$ and $D_{3}$, it suggests that the effects of the price reference policy are higher than the import restrictions issued as part of the self-sufficiency regulation. Though current government practice is to simplify import procedures in order to achieve more efficient business practices, as the regulation explicitly states, this does not mean lowering the restrictions. However, as we can see in the table, import was still carried out during periods of active price reference policy, as the beef price was exceeding the price reference of 76.000 IDR. During July 2013 to December 2015 the average beef price in West Java was at IDR 98.282,36 and at IDR 98.068,03 in Jakarta respectively, i. e. 29\% higher than the reference price. If we compare how these policies effected the price formations of Jakarta and West Java, the effects are generally found to be higher for the West Java market than for Jakarta. This finding may relate to the fact that West Java has the highest beef consumption rate nationwide. Analyzing the effects of price reference policies, as represented by $D_{3}$, we see that the effect is doubled in West Java when compared to Jakarta which where it reaches almost $30 \%$ in West Java.

The results of $T V E C M \mathrm{~s}$ showed that the estimated thresholds are 
quite small for Jakarta, while for West Java the thresholds are a higher resulting in positive threshold values for both Jakarta and West Java. As discussed earlier, the threshold values can be interpreted as transaction costs for importing beef. These findings suggest that the trade costs for importing beef is around $3.5 \%$ in West Java and $0.2 \%$ in Jakarta respectively. These small numbers suggest that importing beef cheaper and therefore more efficient than was to be expected. As mentioned earlier, beef import is distributed through companies with sufficient marketing facilities such as refrigerators and cold storage, as required by the regulation. Since imported beef can only be distributed to segmented markets like hotels, restaurants, and modern supermarkets, low costs can be maintained. In addition, both Jakarta and West Java have good transportation and infrastructure.

Table 3.4: The Results of the TVECM Estimation using the Regularized Bayesian Technique.

\begin{tabular}{|c|c|c|c|c|}
\hline \multirow{2}{*}{ Parameters } & \multicolumn{2}{|c|}{ Jakarta } & \multicolumn{2}{c|}{ West Java } \\
\cline { 2 - 5 } & Lower regime & Upper regime & Lower regime & Upper regime \\
\hline \hline Speed of Adjustment & & & & \\
\hline ect domestic & $-0.1034^{* *}$ & $-0.089^{* *}$ & $-0.123^{* * *}$ & -0.075 \\
\hline ect import & 0.124 & 0.126 & 0.05 & 0.073 \\
\hline No. of observations & 83 & 77 & 116 & 44 \\
\hline Threshold & & 0.002 & & 0.035 \\
\hline
\end{tabular}

Notes: the ect stands for error correction term, ${ }^{* *}$ statistically significant at $5 \%$ level.

As described in the methodology section, the $T V E C M$ s can capture the picture of market integration through the estimation of price transmission elasticity coefficient and speed of price adjustments. As shown in the table, both error correction coefficients have the expected signs. It can be seen that only the error correction coefficients of domestic price are statistically significant suggesting that only domestic price is conducting the adjustment from the disequilibrium condition. However, there is only one statistically significant error correction for West Java. This results may be attributed to the small number of observations estimated in this regime.

Regarding the magnitude of the error correction parameters, the half-live time adjustments to shocks for Jakarta market is calculated 6.70 
months for the lower regime and 7.78 months for the upper regime respectively. Meanwhile, for West Java, the half live time adjustment is 5.63 months for the lower regime. The half-life time adjustment represents the time required for the effect of $50 \%$ of price shocks to phase out. Based on these findings, it suggests that the transmission between import price to domestic price is quite slow. This slow transmission may relate to the import restrictions imposed by the government. In addition, as explained in the previous chapter, there are several technical procedures which should be fulfilled to implement importation in the Indonesian beef industry. According to the regulation, the application for importation is offered four times every year on March, June, September and December with the time required is maximum three months for every application. The importer should also fulfill at least $80 \%$ from the annual application.

\subsection{Conclusions}

By investigating the price transmission processes between import and the domestic prices using the threshold vector error correction model (TVECM) alongside the regularized Bayesian estimation Technique, the empirical results generated above attempt to answer the question, how import policies affect the domestic price formation of the Indonesian beef industry. The results of the long run estimation showed that the price elasticity of the import prices is $48 \%$ for Jakarta and $43 \%$ for west java market suggesting a moderate dependency of Indonesia on the world market.

The study supports the assumption that political interventions play a measurable role in transmission between import and domestic prices. The effect of the implemented regulation gradually increases during the investigated periods. At the same time, the present results prove that the price reference policy is more effective than the import restrictions imposed as part of the self-sufficiency regulation. Furthermore, the magnitude of the estimated thresholds indicates that importing beef is efficient particularly for the Jakarta and West java markets. Merely the error correction coefficients for the domestic price are statistically significant, suggesting that only the domestic price is relevant for adjusting the disequilibrium condition. Accordingly, regarding the magnitude of the error correction parameters, this study suggests a relatively slow transmission between import and domestic prices in the Indonesian beef industry. To conclude, this finding can be an indication that the import regulation imposed by the 
Indonesian government may have resulted in lowering the transmission between import and domestic prices in the beef industry. Therefore, the effectiveness of using importation as a tool for stabilizing domestic price is then questionable. 


\section{Chapter 4}

\section{Spatial Market Integration Analysis in the Indonesian Beef Industry: A Multivariate Approach}

\subsection{Introduction}

Market integration is generally believed to be beneficial to imposing an economic growth and alleviating poverty, particularly in the food sector. For developing countries, the presence of market integration is a crucial point in the context of food security. With a high degree of market integration, a smooth trade flow from the surplus areas to the deficit areas is expected to occur, thus improving the transmission of price signals, diminishing price volatility, and encouraging a more competitive market in which production decision will be based on the comparative advantage (Fackler and Goodwin (2002), Cirera and Arndt (2008)). However, there are several factors which inhibit the existence of market integration in developing countries including, among others, inadequate trading infrastructure, inefficient bureaucracy, and unsupported macroeconomic conditions. All of these three situations contribute to making the transaction cost relatively high and thus stimulate an inefficient market that prevents market integration. In this light, a proper understanding of how well the market is functioning remains crucial as the basis for constructing policy recommendation.

If a market is spatially integrated, prices are transmitted 
simultaneously across regions reflecting the flow of goods and information. An investigation into how price transmission occurs among the prices in various locations is important to spatial policy design. Most studies have conceptualized the integration by emphasizing the tradability (Barret, 2008). However, it is important to note that tradability is not the only requirement for integration. As markets within a single country share some similarities, such as the nationally endorsed the policy, there would be spillover effects among the markets in different locations. As a consequence, a multivariate approach is arguably more suitable than a bivariate approach that is commonly used in various existing empirical studies. This argument is supported by - among others - Gonzalez-Rivera and Hefland (2001), who based their study on an investigation into the Brazilian rice market. They conclude that a bivariate approach is not sufficient to explain market integration. The bivariate model restricts the equation as it merely considers two variables, and thus potentially misspecified the nature of multimarket system. Another disadvantage of the bivariate approach is its inability to identify locations that belong to the same market and share the same long-run information.

Following the approach suggested by Gonzalez-Rivera and Hefland (2001), this study investigates spatial market integration in the Indonesian beef industry using a multivariate approach. Gonzalez-Rivera and Hefland (2001) defines the market integration for $n$ geographically different locations by referring to the condition in which there is a physical flow of goods among the locations which share the same long-run information. This section aims at evaluating the pattern of interdependence among the market locations and the degree of integration. As the object of study, this study focuses on the main producer and consumer areas in the Indonesian beef industry. In the next section, data and methodology are discussed. Subsequently, the empirical results and conclusions are discussed in the final sections.

\subsection{Methodology}

This study examines the existence of spatial market integration with the multivariate approach proposed by Gonzalez-Rivera and Hafeland (2001). The multivariate approach was chosen due to the fact that prices across the regions have spillover effects which may not be captured by a bivariate approach. The first evaluation identifies which regions, among the main producer and consumer areas, are directly or indirectly interconnected 
with each other using the information derived from trade flow data. The monthly beef consumer price data from Statistics Indonesia was used in this study. It covers the periods between 2002 and 2015 and is comprised of 196 observations collected from 9 provinces in Indonesia. All the price series have been transformed into logarithmic form.

Table 4.1: Summary Statistics for The Investigated Price Variables in IDR.

\begin{tabular}{|c|c|c|c|c|}
\hline Price Series & Mean & Standard Deviation & Minimum & Maximum \\
\hline \hline Jakarta (JKT) & 62763 & 21440 & 36340 & 112710 \\
\hline Lampung (LPG) & 60490 & 23914 & 31801 & 116990 \\
\hline Jawa Barat (JBR) & 59786 & 22130 & 34977 & 107710 \\
\hline Jawa Tengah (JTG) & 55339 & 20241 & 30623 & 98017 \\
\hline DIY & 59220 & 22889 & 32900 & 105000 \\
\hline JawaTimur (JTM) & 54610 & 21273 & 29510 & 97967 \\
\hline Bali & 49256 & 22035 & 28000 & 98795 \\
\hline NTB & 53628 & 23005 & 26444 & 105750 \\
\hline NTT & 45948 & 21192 & 19520 & 85854 \\
\hline
\end{tabular}

Note: Source of raw data comes from Statistics Indonesia.

According to Gonzalez-Rivera and Hafeland (2001), there are two points depicted in evaluating spatial market integration. First, the existence of trade among the $n$ market locations either directly or indirectly. Second, for those $\mathrm{n}$ market locations, there should be one common integrating factor implying that those markets share the same long-run information. Suppose that we have $n \times 1$ nonstationary vector of the price series i.e. I(1) $P_{t}=P_{1}, P_{2}, \ldots, P_{n t}$ at time $t$ in market $i$. This $P_{t}$ can be written as:

$$
P_{t}=A_{n \times s} f_{t}+\tilde{P}_{t}
$$

where $f_{t}$ is an $s \times 1$ vector of $s(s<n)$ common unit root factors and $\tilde{P}_{t}$ is an $1 \times n$ vector of stationary components. This equation 4.1 implies the common factor representation if and only if there are $n-s$ cointegrating vector among the elements of the vector $P_{t}$ as depicted in the Engel-Granger representation Theorem. According to this theorem, a cointegrated system can then be explained by a vector of error correction $(V E C)$ model as follows:

$$
\Delta P_{t}=\mu+\Pi P_{t-1}+\Gamma_{1} \Delta P_{t-1}+\Gamma_{2} \Delta P_{t-2}+\ldots+\Gamma_{p-1} \Delta P_{t-p+1}+\epsilon_{t}
$$

where $\Gamma$ and $\Pi$ are the coefficient matrices of $n \times n$ and $\Pi$ has reduced ranks of $n-s$. The matrix of $\Pi$ can be also written as $\Pi=\alpha \beta^{\prime}$ where $\alpha$ is 
an $n \times n(n<s)$ coefficient and $\beta$ is an $n \times n(n<s)$ cointegrated vector. Accordingly, we have $\Pi P_{t-1}=\alpha \beta^{\prime} P_{t_{1}}=\alpha Z_{t-1}$. The interesting point here is the error correction term $Z_{t-1}=\beta^{\prime} P_{t-1}$ with $\alpha$ decribing an adjustment coefficient from the long-run disequilibrium. With this framework, the market integration holds when $s=1$ since we must search for markets which share the same long-run information. As a result, searching for the common factor representation as in 4.1 is equivalent to the searching for $n-1$ cointegrating vectors. The search for $n-1$ cointegrating vectors is conducted in a multivariate framework proposed by Johansen (1998) i.e. the reduced rank of $V A R$ cointegration testing. In addition, to capture the effect of policy during the investigated period, we augment the long-run estimation with the dummy variable, namely, policy, which represents the implementation of the import-price reference policy.

The pattern of interdependence among the investigated markets is observed through the analysis of $V E C M$ which provides the estimations of adjustment coefficients (i.e. $\alpha$ ). The $V E C$ in equation (4.2) summarizes the short-run dynamics of the vector $P_{t}$ as a function of $\alpha$ past disequilibrium (speed of adjustment coefficient) and the lags of $P_{t-1}$ for every $\Delta P$. The matrix of speed adjustment contains information about the spatial structure of the market. This can be observed by looking at which coefficient is statistically significant which will indicate the reactions to other markets. For example, if all $\alpha$ are found to be statistically significant, it means that every market location reacts to every disequilibrium of every other location. Another point to be considered is whether there are one or more exogenous market locations which dominate the long-run behavior of the system. This case is shown when the error correction term coefficient in the $V E C$ i.e. $\alpha_{i j}$ for market location $i, j=1,2, \ldots, n-1$ is statistically zero, this is known as the test for weak exogeneity. The failure to reject the null of weak exogeneity i.e. $H_{0}: \alpha_{i j}=0$ implies the presence of an exogenous location which by itself later becomes an integrating factor of the system.

The next empirical question is the assessment of the degree of integration. Within the existing market integration literature, the degree of integration is commonly measured by looking at the size of the speed of adjustment and the statistical significance of the lag structures. Furthermore, the evaluation of this purpose in a single measure is generally performed using the impulse response factor $(I R F)$ which can trace the impact of a shock from one location to another location over time. However, when the shocks are correlated, it is difficult to find one unique result. In the existing literature, the strategy to overcome this situation is 
conducted by orthogonalizing the shocks using Cholesky decomposition of the covariance matrix of the errors. This orthogonalization results in the variation of $I R F$ of every order. However, as a consequence, it is sometime difficult to justify the ordering and to interpret the results.

In brief, our estimation steps can be summarized as follows. First, the time-series properties of the data were checked using the Augmented Dickey-Fuller unit root test. Then, after checking for the time series properties, an investigation into the presence of one common integrating factor for the price series was conducted using the Johansen cointegration test. After obtaining the number of cointegration, we employed a multivariate vector error correction model ( $V E C M)$ to draw the pattern of interdependence among the markets and the degree of integration. Furthermore, generalized forecast error variance decomposition (GFEVD) are presented as well.

\subsection{Findings}

As summarized in the Table 4.2, according to the Augmented DickeyFuller $(A D F)$ unit root test with time trend included, all the investigated beef prices are found to be integrated of order one i.e. $I(1)$.

Table 4.2: The Results of Unit Root Tests by ADF Test.

\begin{tabular}{|c|c|c|}
\hline Price Variable & Level & First Difference \\
\hline \hline Bali & -2.161 & $-3.984^{* * *}$ \\
\hline DIY & -3.016 & $-4.043^{* * *}$ \\
\hline JBR & -3.013 & $-10.638^{* * *}$ \\
\hline JKT & -3.411 & $-10.413^{* * *}$ \\
\hline JTG & -2.062 & $-10.153^{* * *}$ \\
\hline JTM & -2.014 & $-12.000^{* * *}$ \\
\hline LPG & -3.560 & $-9.152^{* * *}$ \\
\hline NTB & -3.102 & $-12.315^{* * *}$ \\
\hline NTT & -3.112 & $-10.412^{* * *}$ \\
\hline
\end{tabular}

Notes: The number represents the $t$-statistics of the $A D F$ test, the null hypothesis contains unit roots, and the number of lags is selected by $A I C$, ***Statistically significant at $1 \%$.

According to the results of the Johansen cointegration tests, as shown in the Table 4.3, out of the nine market locations which were investigated, 
there are eight cointegration vectors implying the presence of one common integrating factor for the price series i.e $n-1$ cointegrated vectors. Both constant and trend results are also presented in Table 4.3.

Table 4.3: The results of Johansen Cointegration Test.

\begin{tabular}{|c|c|c|c|c|}
\hline \multirow{2}{*}{$R_{0}$} & \multicolumn{2}{|c|}{ Constant } & \multicolumn{2}{c|}{ Constant and Trend } \\
\cline { 2 - 5 } & LR & $p$-value & LR & $p$-value \\
\hline \hline 0 & 243.74 & 0.0002 & 229.20 & 0.0445 \\
\hline 1 & 178.69 & 0.0141 & 168.37 & 0.3064 \\
\hline 2 & 121.68 & 0.2266 & 119.47 & 0.6948 \\
\hline 3 & 90.31 & 0.2810 & 89.12 & 0.7301 \\
\hline 4 & 65.97 & 0.2592 & 64.73 & 0.7092 \\
\hline 5 & 45.57 & 0.2323 & 45.38 & 0.6315 \\
\hline 6 & 29.03 & 0.2002 & 28.64 & 0.5885 \\
\hline 7 & 14.69 & 0.2500 & 14.35 & 0.6341 \\
\hline 8 & 5.42 & 0.2496 & 5.58 & 0.5243 \\
\hline
\end{tabular}

Notes: number of lags is selected by $A I C$.

The restricted $M V E C M$ in equation (4.2) is estimated using the Johansen procedure (1993) which is imposed over-identifying restrictions based on the theoretical expectations. The normalization is conducted based on the assumption that Jakarta (JKT) holds an important position as a reference market in the food industry in general. Therefore, all long-run relations are expressed relative to JKT. The following Figure 4.1 depicts the percentage of beef which is traded for the respective market locations. As seen in the figure, beef markets are dominated by Jakarta. Most of the traded beef entering Jakarta from other regions. 
Figure 4.1: Beef Trade Profile of the Selected Markets during 2006-2015.

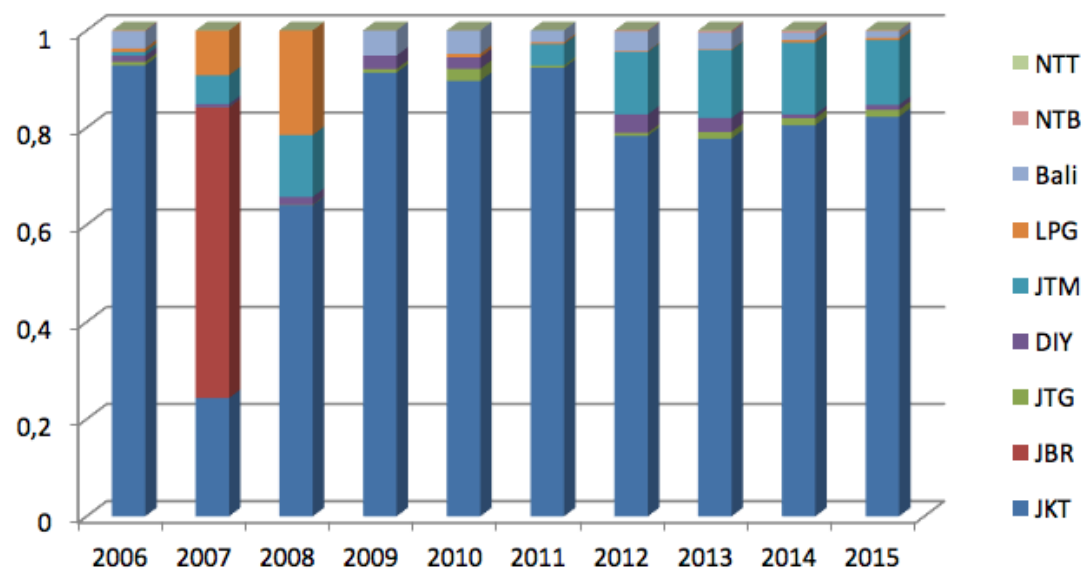

Source: Calculated from Statistics Indonesia (2015)

Table 4.4 shows the eight estimated cointegrating vectors which can be interpreted as pair-wise relationships. For our system, the long-run relationships become $P_{i t}=\beta_{0}+\beta_{1} P_{J K T}+\beta_{2}$ Policy $+z_{i t}$. Therefore, in the case of Lampung (LPG), for instance, we have $P_{L P G}=2.681-1.247 P_{J K T}+0.07$ Policy $+z_{i t}$. As shown in the table, the value of $\beta_{1}$ is close to unity which ranging from -0.844 to -1.792 . In most cases, the hypothesis of $\beta_{1}=1$ cannot be rejected at the $5 \%$ level. Cointegrating vectors may differ from $(1,-1)$ as a result of transaction costs alongside other reasons. For the case of the Indonesian beef industry, as already mentioned previously, the market is generally characterized by the spatial arbitrage which occurs indirectly through the cattle markets. Due to the lack of trading facilities, beef is not commonly traded across regions, but live-cattle are traded and slaughtered in the consumer regions. However, the findings reveal the presence of market integration among the investigated market locations as expected. In addition, as seen in the table, the dummy of policy variable which represents the import-reference price policy in 2013, is found to be statistically significant in the long-run estimation of JTM, Bali, and NTT. According to the sign of the estimated coefficient, the effect of the policy is negative for JTM and Bali, while a positive effect is found in NTT. Furthermore, the effect of this policy is found to be highest in NTT i.e. $43 \%$, and lowest in JTM i.e. $21.7 \%$.

Table 4.5 summarizes the speed of adjustment estimated from the 

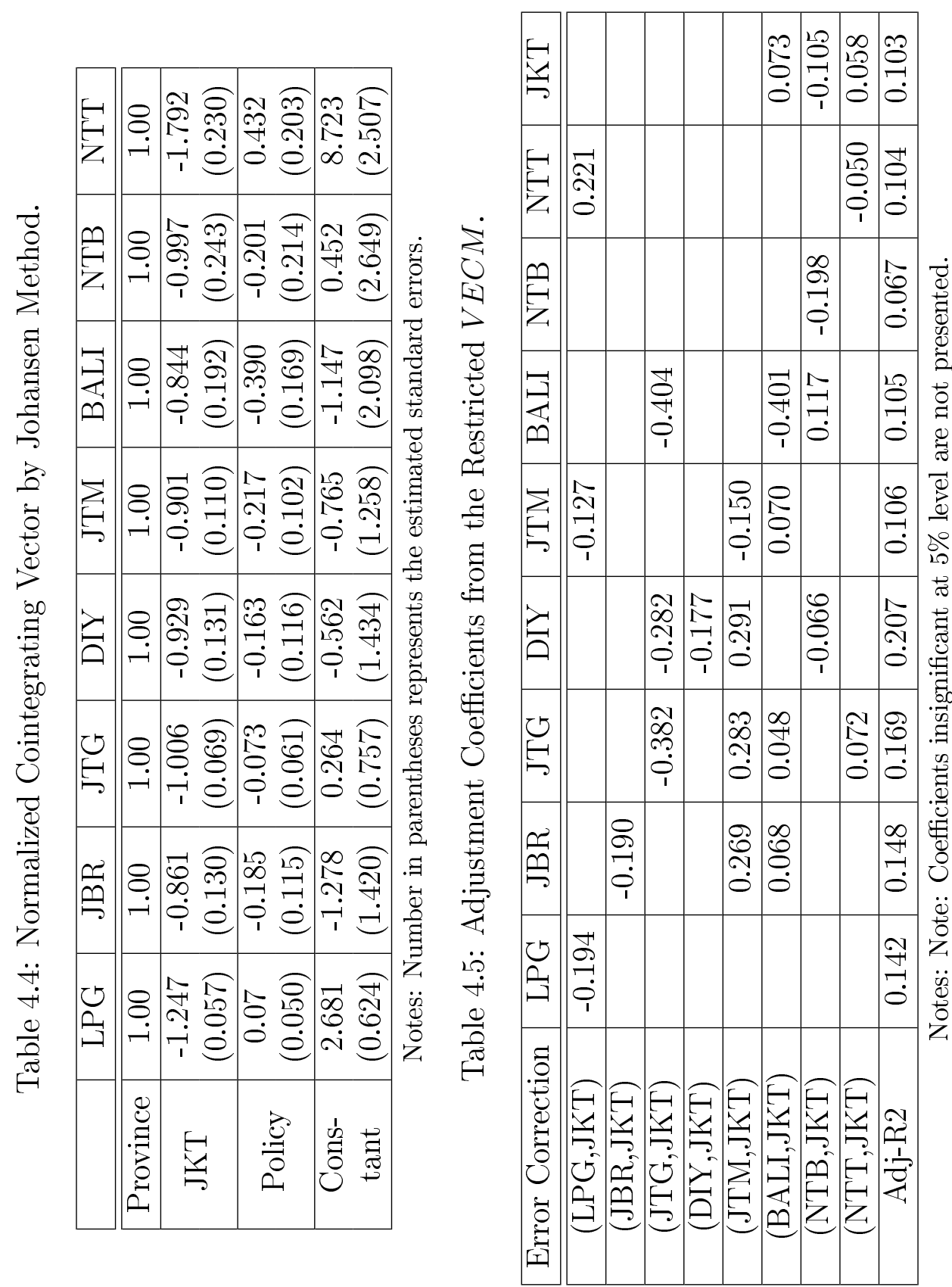
restricted multivariate $V E C M$ which is able to show the pattern of market interdependence. To ensure that our model is not misspecified, we conduct the Lagrange multiplier test for serial correlation, the RESET test for functional form, as well as the $G A R C H$ and White test for testing heteroskedasticity and the Chow test for model stability. The results indicate that there is no evidence of serial correlation and/or seasonal patterns in the residuals for the $V E C M$, confirming that the lag structure is appropriate in capturing the price dynamics. Meanwhile, according to the Chow test, there is no indication of a stability problem in the conditional mean. Regarding the heteroskedasticity, we use heteroskedasticity-consistent standard errors to deal with it.

In order to explore the spatial pattern of market interdependence, it is necessary to investigate the presence of weak exogenous market locations in the system. To do so, several $F$-tests are conducted and followed up by Granger causality tests on the estimated coefficient of the unrestricted $V E C M$. Weak exogeneity of a particular market location implies that there is no price reaction of a particular market to the disequilibrium of other market location. Consequently, in the VEC equation (4.2) we should find the statistically insignificant adjustment coefficients corresponding to all error correction terms which are all equal to zero. Subsequently, it will be followed by the absence of Granger causality. Granger causality proposes that price is linearly influenced by the lag variables of other market locations. As a result, among the investigated market locations, there is no evidence of weak exogenous market locations in the system.

As seen in the Table 4.5, the findings propose various interactions among the investigated market locations. Even though we do not find evidence of weak exogeneity, the findings reveal that not all market locations are interacted with. There are two market locations which only adjust to their own disequilibrium i.e. LPG and NTB. Nevertheless, as a general picture, it is found that producer regions are interacted with. Meanwhile, if we look at the main consumer areas i.e. JKT and JBR, the adjustments are different. Both regions only adjust to the producer regions. JBR is adjusting to JTM and Bali, while JKT is adjusting to Bali, NTB, and NTT. Generally, the pattern of market interdependence as described in this study, has been confirmed by the trade pattern among the market locations. For instance, for JKT, the beef supply mainly comes from Bali, NTB, and NTT. In addition, the interaction is also associated with the geographical location, in which market locations tend to react to their neighboring markets, for example in the case of DIY and JTG. 
Table 4.6: The Estimated Half-Life Time (months) from the VECM.

\begin{tabular}{|c|c|c|}
\hline Market & Restricted & Unrestricted \\
\hline \hline LPG & 3.57 & 3.39 \\
\hline JBR & 1.31 & 1.35 \\
\hline JTG & 0.97 & 0.99 \\
\hline DIY & 0.85 & 0.88 \\
\hline JTM & 3.15 & 6.93 \\
\hline BALI & 0.75 & 0.77 \\
\hline NTB & 3.50 & 3.59 \\
\hline NTT & 2.55 & 2.59 \\
\hline JKT & 2.93 & 3.06 \\
\hline
\end{tabular}

Notes: numbers are the p-values. The null hypothesis is no-cointegration.

With regard to the magnitude of the speed of adjustments, we calculated the half-life time derived from the $V E C$ model which represents the time required for the effect of $50 \%$ of price shocks to phase out. Generally, both the restricted and unrestricted $V E C$ models, show similar results, except for JTM. According to the results, there are two points that can be depicted as seen in the Table 4.6. First, the market locations in which half life time is less than two months i.e. JTG, DIY, Bali and JBR. Second, the market whose half life time is more than two months (near three months) i.e. LPG, JTM, NTB, NTT, and JKT.

As an additional explanation to the degree of integration among the market locations, we provide the Forecast Variance Error Decomposition ( $F V E D)$. The $F V E D$ measures how much the forecast error variance of each variable can be explained by shocks of the other variables after $n$ periods. For instance, as shown in the Table 4.7 , in period 24, the proportion of the impact accounted for by innovations in each market location of the total impact of innovations in JKT is dominated by JBR which is accounted for $24.18 \%$. For a complete picture of FVED can be seen in the Figure 4.2.

\subsection{Conclusions}

In this section, we investigate the spatial market integration in the Indonesian beef industry with a focus on the main consumer and producer 

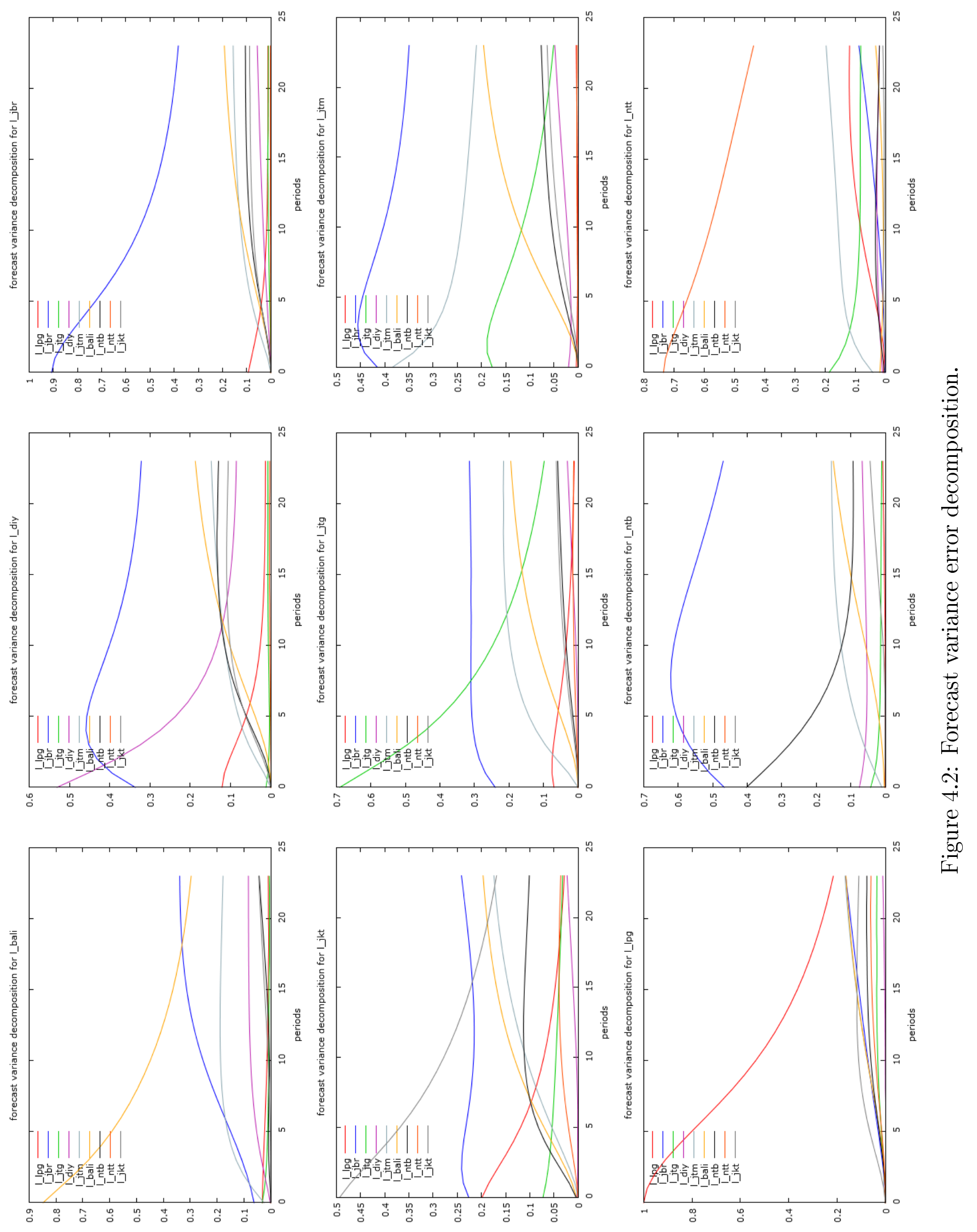
Table 4.7: Forecast Variance Error Decomposition for JKT.

\begin{tabular}{|c|c|c|c|c|}
\hline Market & Period 3 & Period 6 & Period 12 & Period 24 \\
\hline \hline LPG & 16.74 & 11.87 & 6.49 & 2.84 \\
\hline JBR & 24.10 & 23.22 & 21.49 & 24.18 \\
\hline JTG & 6.19 & 5.35 & 4.46 & 3.18 \\
\hline DIY & 0.09 & 0.054 & 0.46 & 2.26 \\
\hline JTM & 1.70 & 5.43 & 11.63 & 17.42 \\
\hline BALI & 2.50 & 7.04 & 14.14 & 19.65 \\
\hline NTB & 3.59 & 8.21 & 11.25 & 10.087 \\
\hline NTT & 0.65 & 1.99 & 3.64 & 3.59 \\
\hline JKT & 44.46 & 36.81 & 26.44 & 16.85 \\
\hline
\end{tabular}

Notes: numbers are the p-values. The null hypothesis is no-cointegration.

regions between 2002 and 2015. By employing a multivariate approach, the empirical findings suggest the existence of market integration among the investigated market locations. A multivariate Vector Error Correction Model $(V E C M)$ is estimated to assess the degree of integration as well as the pattern of market interdependence. Due to the implementation of the import-price reference policy in 2013, we modify a dummy policy as an exogenous variable in the long-run estimation of the $V E C M$. The findings suggest its effect are found to be statistically significant in three producer regions i.e. JTM, Bali, and NTT. Furthermore, the effect of the import-price reference policy is different for those three regions both in the sign and the magnitude.

With regard to the pattern of market interdependence, the results highlight the interaction between the producer areas. It suggests that producer areas adjust to any disequilibrium from other producer regions. Consumer regions also adjust to producer regions in similar manner, but there is no evidence of adjustment from producer regions to consumer regions. Among nine of the investigated market locations, there are two producer regions which only adjust to their own disequlibrium i.e. LPG and NTB. The pattern of market interdependence resulting from this analysis confirms the trade pattern among the investigated markets. In addition, markets will likely react to other markets which share the same border i.e. those which have a geographically related distance. To conclude, these findings emphasize the role of tradability in spatial market integration. As 
a policy implication, the government should pay more attention to the producer areas when imposing policy. Besides that, based on the findings, the improvement of marketing infrastructure is necessary for increasing market efficiency. 


\section{Chapter 5}

\section{Price Transmission along the Supply Chain}

\subsection{Introduction}

The study of price transmission analysis along the supply chain for food products, also known as vertical price transmission analysis, has been analyzed in various existing agricultural economic literature for years. There are some underlying grounds that explain the importance of a vertical price transmission study. First, price changes along the marketing chain have implications for economic welfare (Sexton and Lavoie, 2001). As a common assumption in the economics, the price represents product availability, which means that investigating price movement along the marketing chain would serve as a signal as to whether the allocation of resources in agricultural food production is efficient or not (Friedman, 2007). In addition, price transmission analysis results can be useful for portraying price competition in the food sector; this would therefore be an interesting point for competition authorities and policy makers (Bakucs and Fertő, 2013). Among the existing literature, the study of vertical price transmission in the beef industry is commonly conducted in developed countries, such as the USA, Australia, and some European countries. A number of scholars, for instance, have attempted to provide indications of asymmetric behavior in the price transmission along the supply chain (McCorriston 1998; Peltzman 2000). Accordingly, Meyer and Von-Cramon Taubadel (2004) have provided a comprehensive review of asymmetric price transmission. However, studies analyzing the case of developing countries are still few. 
This chapter analyzes price behavior in Indonesia's beef supply chain by investigating the transmission process between retail beef and cattle price. One of the key features of the Indonesian beef industry is that live cattle are traded across the regions to fulfill the demand of beef. As a common fact found across developing countries, the Indonesian beef industry is mainly characterized by the domination of smallholders and a large number of intermediaries along the value chain. Moreover, due to geographical conditions and a lack of good infrastructure, high transportation costs have become the main problem for the Indonesian beef industry. In a manner consistent with the analyses conducted in the two previous chapters, this chapter also scrutinizes some relevant policies imposed on the beef industry. Particular attention is given to see how changes in producer prices are transmitted to the consumer, and who will undertake the adjustment from the disequilibrium. In addition, the effects of some policy measurements are also investigated.

Price transmission analysis has been commonly conducted using time series data. Most analyses employ a cointegration model as they assume that the commodity price is generally characterized as a non-stationary variable that contains a stochastic trend. In addition, commodity prices also tend to move together over time so the prices are called cointegrated (Asche, Flaaten, Isaksen, \& Vassdal, 2002; Hassouneh, Cramon-taubadel, Serra, \& Gil, 2012). However, using time series data would be challenging for the case of developing country, like Indonesia, especially considering the issue of data availability. In an alternative approach to deal with this issue, this study is carried out using panel approach. This represents a divergence from the typical empirical investigation can carry out in existing literature. The use of panel data with both large numbers of cross-sections and time series is called a macro panel. Such a technic has been applied in several recent studies to gain more power by not only calculating the time series dimension, but also the cross section dimensions. Another advantage offered by a panel cointegration approach is its ability to accommodate heterogeneity across the regions and to deal with the issue of stationary. Baltagi and Kao (2000) provided a comprehensive survey on the use of panel data with nonstationary variables.

Assuming the various market characteristics among the regions, this study employs a Panel Heterogenous Dynamic Model using pooled mean group estimators $(P M G)$ developed by Pesaran and Shin (1999). The idea of this $P M G$ estimation centers on restricting the long-run equation to be equal across the groups but allowing the short run dynamics to be heterogeneous. 


\subsection{Data and Methodology}

An eight-year panel data (2008 - 2015) derived from 32 provinces in Indonesia with monthly series provided by Statistics Indonesia is used in this study. The farm price data is obtained from live cattle price at the farm gate level, which is then converted into Rupiah (Indonesian currency) per kilogram. Both farm and retail prices are the price for rural areas. Consequently, Jakarta as the capital city of Indonesia is excluded in this study.

Table 5.1: Summary Statistics of Variables.

\begin{tabular}{|c|c|c|c|c|}
\hline Variable & Mean & Std. Dev & Min & Max \\
\hline \hline Retail Beef price $(P r)$ & 74101.43 & 16137.58 & 44650 & 127250 \\
\hline Cattle price $(P f)$ & 26721.2 & 5484.235 & 16000 & 45308.56 \\
\hline
\end{tabular}

Source: Own Calculation.

There has been an increasing interest in the study of dynamic panel data in which the number of cross section observations $(N)$ and the number of time series observations are both large. The long-run and short-run coefficients are of interest in most of the applications. Assuming an Autoregressive Distributive Lag $(A R D L)\left(p, q_{1}, \ldots, q_{k}\right)$, the dynamic panel specification is of the form:

$$
Y_{i t}=\sum_{j=1}^{p} \lambda_{i j} Y_{i, t-j}+\sum_{j=0}^{q} \delta_{i j}^{\prime} X_{i, t-j}+\mu_{i}+\epsilon_{i t}
$$

where the number of groups is $i=1,2, \ldots, N$; the number of periods is $t=1,2, \ldots, T ; Y_{i t}$ is the dependent variable, $X$ is the $k \times 1$ vector of independent variables, $\delta_{i j}$ is the $k \times 1$ vector coefficients, $\lambda_{i j}$ are the scalars, and $\mu_{i}$ is the group specific effect.

If the variables are $I(1)$ and cointegrated, then the error term is $I(0)$ for all $i$. The main point of the analysis of cointegrating variables is the variables' responsiveness to any deviation from the long-run equilibrium. Implicitly, this proposes an error correction model in which the short run dynamics of the variables are influenced by the deviation from equilibrium. Thus, it is common to re-parameterize (5.1) into the error correction 
equation:

$$
\Delta Y_{i t}=\alpha_{i}\left(Y_{i, t-1}-\theta_{i}^{\prime} X_{i t}\right)+\sum_{j=1}^{p-1} \lambda_{i j}{ }^{*} \Delta Y_{i, t-1}+\sum_{j=0}^{q} \delta_{i j}{ }^{*} \Delta X_{i, t-j}+\mu_{i}+\epsilon_{i t}
$$

where

$\alpha_{i}=-\left(1-\sum_{j=1}^{p-1} \lambda_{i j}\right), \theta_{i}=\sum_{j=0}^{q} \delta_{i j} /\left(1-\sum_{k} \lambda_{i j}\right), \lambda_{i j}{ }^{*}=-\sum_{m=j+1}^{p} \lambda_{i m}$, $j=1,2, \ldots, p-1$

and

$\delta_{i j}{ }^{*}=-\sum_{m=j+1}^{q} \delta_{i m}, j=1,2, \ldots, q-1$.

The parameter $\alpha_{i}$ is the error correcting adjustment term. If $\alpha_{i}=0$, then there is no evidence of a long-run relationship between the variables.

The equation (5.1) and (5.2) are applied to analyze cattle-beef price transmission as expressed by the following model:

$$
\begin{gathered}
P f_{i t}=\theta_{0}+\theta_{1} i P r_{i t}+B S S P+\text { RefPrice }+\epsilon_{i t} \\
\Delta P f_{i t}=\alpha_{i}{ }^{f}\left(P f_{i, t-1}-\theta_{1_{i}} P r_{i t}-B S S P-\text { RefPrice }\right) \\
+\sum_{j=1}^{p-1}\left(\lambda_{i j} \Delta P f_{i, t}, t-1\right)+\sum_{j=1}^{p-1}\left(\lambda_{i j} \Delta P r_{i}, t-1\right)+\mu_{i}+\epsilon_{i t} \\
\Delta P r_{i t}=\alpha_{i}^{r}\left(P f_{i, t-1}-\theta_{1_{i}} P r_{i t}-B S S P-\operatorname{RefPrice}\right) \\
+\sum_{j=1}^{p-1}\left(\lambda_{i j} \Delta P r_{i, t}, t-1\right) 0+\sum_{j=1}^{p-1}\left(\lambda_{i j} \Delta P r_{i}, t-1\right)+\mu_{i}+\epsilon_{i t}
\end{gathered}
$$

where $P f$ is the logarithm of cattle price and $P r$ is the logarithm of the retail beef price. Equation (5.3) shows the long-run relationship between the price, while equation (5.4) and (5.5) represent the error correction model. In order to capture the role of policy, the long-run equation was modified with two dummy variables representing the respective policy i.e. BSSP that represents the regulation related to Beef Self-sufficiency policy imposed from 2010 to 2013, and Refprice that represents the price reference policy from 2013 to 2015. 
The adjustment parameters $\alpha_{i}{ }^{f}$ and $\alpha_{i}{ }^{r}$ measure the speed at which price transmission takes place. The cointegration between $P f$ and $P r$ requires different sign of the adjustment parameters i.e. if $\alpha_{i}{ }^{f}<0$ then $\alpha_{i}{ }^{r}>0$. As an example, if $P f$ is too high with respect to $\operatorname{Pr}$, then $\alpha_{i}{ }^{f}<0$ and $\alpha_{i}{ }^{r}>0$ to ensure that $P f$ will decrease and $P r$ will increase in the next period, and thus guide those prices to come back to the long-run equilibrium. In the price transmission analysis, it is expected that $0<\left(\alpha_{i}{ }^{f}+\alpha_{i}^{r}\right) \leq 1$. If $\left(\alpha_{i}{ }^{f}+\alpha_{i}^{r}\right)=1$, this means that any changes of $P f$ and $\operatorname{Pr}$ will completely correct any deviation from the long-run equilibrium within one period. Hence, the closer the magnitude of the adjustment parameter is to 1, the more rapid the price adjustment is from any deviation from the long-run equilibrium.

This chapter follows Pesaran and Smith's suggestion to estimate the long-run and the short run coefficients, namely Pooled Mean Group (PMG) estimator proposed by Pesaran and Shin (1999). The common estimation approach used in the existing literature is the Dynamic Fixed Effects technique in which the time series data for each group is pooled and only allows different intercepts for each group. The problem with this DFE approach is when the slope coefficient is in fact, not identical so that the result could be potentially misleading. On the other hand, the $M G$ estimator proposed by Pesaran and Shin (1999) allows different intercepts, coefficients, as well as error variance across the groups. With this approach, the model is fitted separately for each group and a simple arithmetic average of the coefficients is calculated. The $P M G$ estimator is an intermediate technique that combines both averaging and pooling so that it allows different coefficients and error variance across the panels, but constrains the long-run coefficient to be identical across the groups. As the $P M G$ parameters are nonlinear, they are estimated using the maximum likelihood method for each cross section's likelihood.

The use of the $P M G$ estimator is arguably suitable with the nature of Indonesia's beef industry that is characterized by varied market conditions from one region to another, particularly with regard to geographical conditions. Furthermore, assuming one country as one marketing system that plays under the same market-related policy across the regions, restricting the long-run parameter to be identical is assumed to be a good choice when modeling the cattle-retail beef price transmission. 


\section{$5.3 \quad$ Findings}

The issue that arises in the use of panel data with both large time series and cross section dimensions is that the variable of interest is usually nonstationary at the level. There are various ways to test for the presence of unit root in the panel time series data analysis, for instance, Levin-Lin-Chu (2002); Harris Tzavalis (1999); Breitung (2000); Breitung and Das(2005); Im-Pesaran-Shin (2003); Fisher-type (Choi, 2001); and Hadri's (2000) Lagrange Multiplier $(L M)$ tests. The first five tests impose the null hypothesis that all panels contain a unit root, while in the Hadri $L M$ test, the null hypothesis proposes that all panels are (trend) stationary and the alternative hypothesis is that at least some of the panels contain unit roots.

There are several differences in the application of the aforementioned panel unit root tests. Firstly, the Levin-Lin-Chu $(L L C)$, Harris Tsavalis $(H T)$, and Breitung tests simplify the assumption that all panels have the same autoregressive parameters such that $\rho_{i}=\rho$ for all $i$. Meanwhile, Im-Pesaran-Shin (IPS) and Fisher-type tests allow the autoregressive parameter to be panel specific. Secondly, there are differences in the assumption about the rates at which the number of $N$ and $T$ are used, whether they tend to be infinity or fixed. Another difference is that $L L C$, $H T$, and Breitung tests require the panel to balanced, while IPS and Fisher-type tests permit the unbalanced panel to be assessed.

As summarized in Table 5.2, several types of panel unit root test were applied to investigate whether the variables are stationary at both level and the first difference. The tests were specified by including time trend and by subtracting cross-sectional means to deal with cross sectional dependence issue. Meanwhile, the lags structure which is used for $A D F$ regression is referred to as the Akaike Information Criteria $(A I C)$. The results surprisingly show that all price variables are already stationary at level i.e. $I(0)$ as the null hypothesis of unit roots is rejected for all statistics.

After checking the stationary condition of the investigated variables, a test for the presence of panel cointegration between the price variables was conducted. This study applied panel cointegration techniques developed by (Westerlund, 2007). The main idea is to test the null hypothesis of no-cointegration by inferring whether the error correction term in the conditional error correction model is equal to zero. If the null hypothesis of no-error-correction is rejected, then the null hypothesis of no-cointegration 


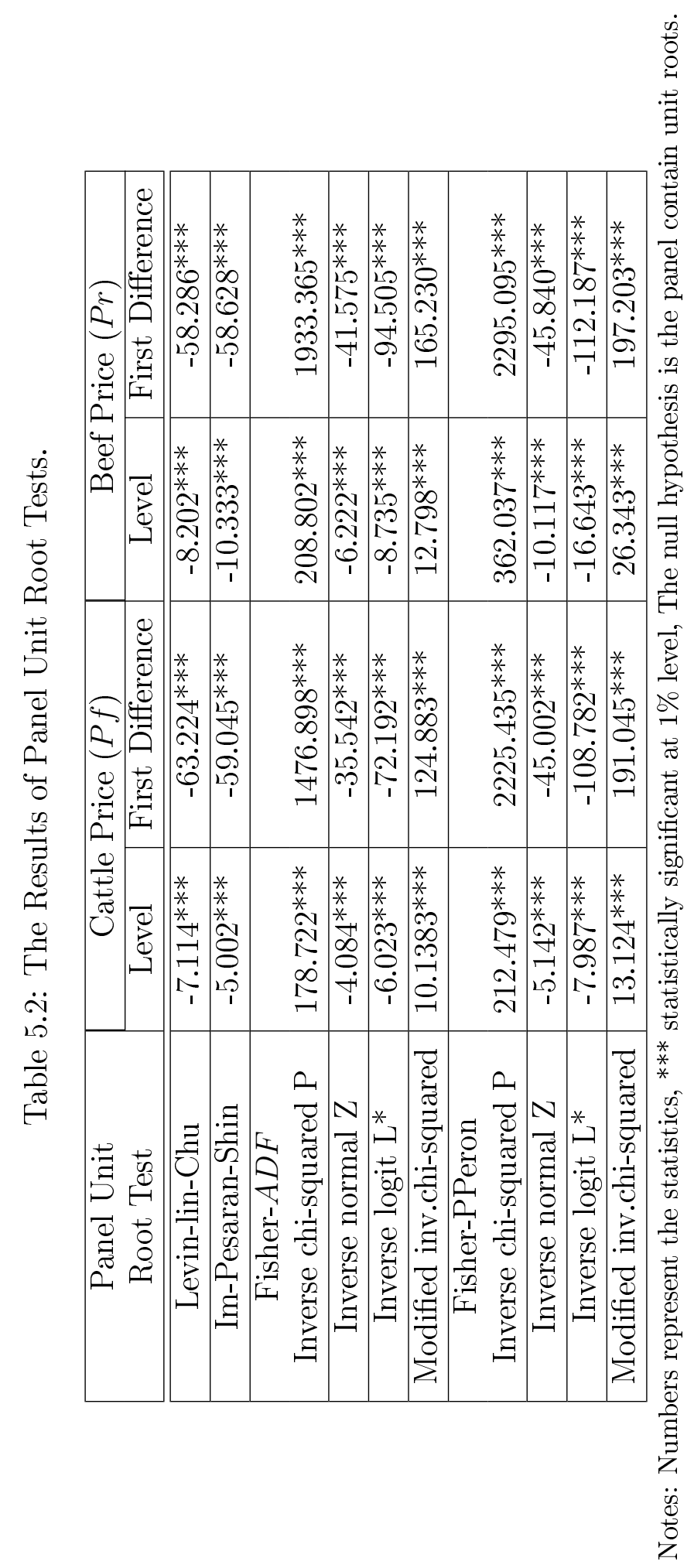


is rejected as well. In contrast to the most residual based cointegration test (Pedroni, 1999; Kao, 1999; McCoskey \& Kao, 1997; Pedroni, 2004) that requires long-run cointegration vectors for the variables at their levels to be equal to the short-run parameters in their difference, known as common factor restrictions, Westerlund (2007) developed four panel cointegration tests that are based more on structural dynamics. Each test can accommodate unit specific short run dynamics, unit specific trend and slope parameters, and cross-sectional dependence. The two tests are designed to test the alternative, whether the panel is cointegrated as a whole; whereas the other two test the alternative that at least one unit is cointegrated. As shown in the following Table 5.3, it is found that the price series are cointegrated.

Table 5.3: The Results of Westerlund Panel Cointegration Tests.

\begin{tabular}{|c|c|c|c|}
\hline Statistics & Value & $z$-value & $p$-value \\
\hline \hline $\mathrm{Gt}$ & -3.738 & -5.511 & 0.000 \\
\hline $\mathrm{Ga}$ & -24.310 & -10.555 & 0.000 \\
\hline $\mathrm{Pt}$ & -34.748 & -26.552 & 0.000 \\
\hline $\mathrm{Pa}$ & -59.465 & -47.835 & 0.000 \\
\hline
\end{tabular}

The results of long-run estimation as defined in equation (5.3) are presented in Table 5.4. This study finds that the long-run elasticity of the retail beef price with respect to cattle price is $42.6 \%$ (i.e. $\theta-1$ ). Some points concerning this magnitude can be depicted. As proposed by Gardner (1975), in a competitive food industry, elasticity price transmission (EPT) approaches unity, it suggests the existence of perfect competition. On the contrary, an EPT which is close-to-zero proposes market segmentation where competition is avoided, which leads to a non-price competition strategy. However, as Kinnucan et al (2015) proposed, the notion that an EPT equal to unity reflects perfect price transmission remains obscure. In his paper, Gardner (1975) also mentioned that even though farm production and the marketing industry are perfectly competitive and have constant returns to scale, this does not guarantee the existence of a unique and stable relationship between farm and retail food price. In most empirical findings, for example, George and King (1971), Wohlgenant (2001), and Asche et al (2002), the EPT of retail-farm price is less than one. Furthermore, Kim and Ward (2013) investigated an extensive empirical analysis in the US food sector with 100 food products included and found that although farm-retail price linkages are strong, they tend to 
decline over time. This situation is indeed in line with the growing market power of intermediaries within the supply chain.

Table 5.4: The Results of Long-Run Estimation by PMG Estimator.

\begin{tabular}{|c|c|c|}
\hline The Estimated Variables & Coefficient & Standard Error \\
\hline \hline $\operatorname{Pr}$ & $1.426^{* * *}$ & 0.267 \\
\hline BSSP & $0.405^{* * *}$ & 0.039 \\
\hline Reference price & $0.474^{* * *}$ & 0.054 \\
\hline
\end{tabular}

Notes: ${ }^{* * *}$ statistically significant at $1 \%$ level.

As discussed earlier, in order to capture the effect of policy, two dummy variables were modified, namely $B S S P$ and the Reference price in the long-run estimation as shown in equation (5.3). As illustrated in the Table 5.4, both dummy variables are found to be statistically significant, with quite similar magnitudes. $B S S$ represents the policy imposed by the government in favor of self-sufficiency in the beef industry, starting from the beginning of 2010. Meanwhile, the Reference price policy relates to import decisions based on a predetermined price during the period between 2013 and 2015. Both policies resulted in situations where markets are restricted from importation. Based on this finding, it can be concluded that these two policies have implications for the price transmission between the cattle price and retail beef price. Furthermore, it also suggests that the price reference policy has a larger effect than the self-sufficiency policy.

The following Figure 5.1 summarizes the speed of adjustments by the $P M G$ estimator. As a general picture, this study reveals that the magnitude of the speed of adjustment is quite low, i.e. less than $10 \%$ for most cases. As shown in Table 5.5 below, the average speed of adjustment is estimated at $5.9 \%$ for the retail beef price and $5.3 \%$ for the cattle price. This slow speed of adjustment suggests an indication of price rigidity in the Indonesian beef industry. Price rigidity can result in a situation where actors in the supply chain tend to not react to the price movements in the market, reflecting the decision to buy or to sell the respective products. From the supply side, producer price rigidity indicates high capital and investment in the industry so that producers cannot adjust quickly to every change in the industry. Accordingly, from the demand side, retail price rigidity reflects consumers' preference towards the product. In the case of Indonesian beef, the evidence on retail beef price rigidity is argued to be associated with the increasing 
demand for beef. Even though beef is considered to be a luxury food product, the demand is growing alongside changes in socioeconomic conditions.

Figure 5.1: The Estimated Speed of Adjustments by PMG estimator.

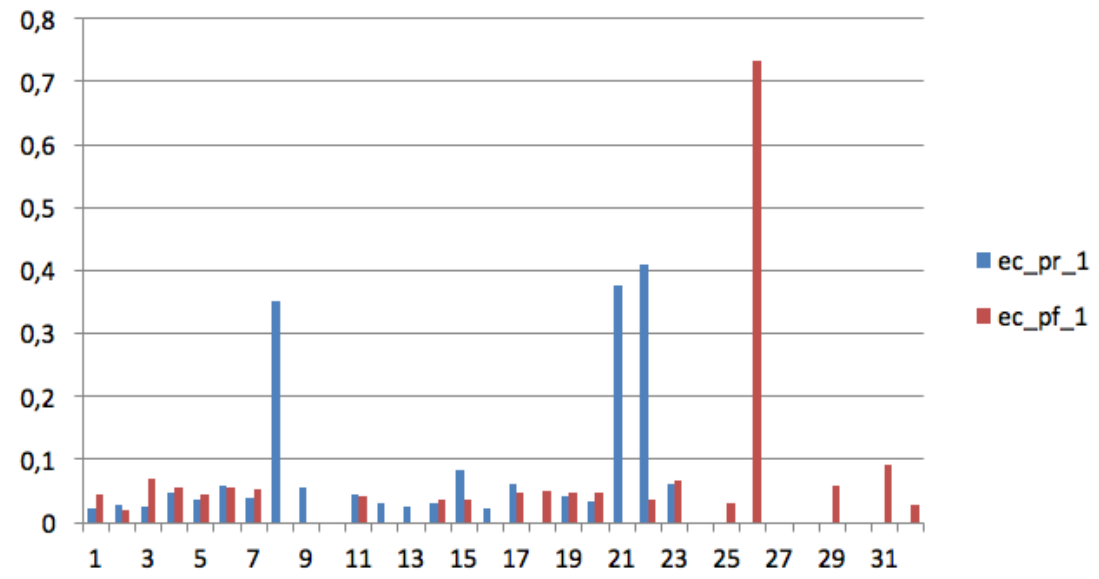

Notes: The insignificant ECTs are considered as 0 .

As shown in Figure 5.1, it is interesting to note that there are some regions that exhibit higher parameters of the error correction term than the average estimations. These regions are Lampung, East Kalimantan (Kaltim), and South Kalimantan (Kalsel) in the case where the retail beef price adjusts. This finding is quite surprising, especially for Kalimantan, because its provinces are neither characterized as beef producer nor consumers. In addition, due to geographical factors, the infrastructure in Kalimantan province is generally underdeveloped in comparison other provinces. Furthermore, surprising findings are also captured in South-east Sulawesi (Sultra) where the cattle price reacts with a high speed of adjustment of up to $73 \%$.

According to the statistically significance error correction term $(E C T)$, this study provides evidence that among 32 provinces, there are 16 regions with both statistically significant ECTs and 5 regions with no significant ECTs. In addition, there are also five regions where the retail beef price $(P r)$, as well as the cattle price $(P f)$, are the only significant parameters. These statistical significances provide the required information to determine which price will react to long disequilibrium. If we look at the main cattle producer areas, various indications are found. First, for East Java, Central 
Java, and NTB, the adjustments are conducted by both prices. Meanwhile, in the case of Bali, the adjustment is conducted by the retail beef price. Furthermore, the cattle price adjusts in NTT. Accordingly, with regard to the magnitude, the adjustments of retail beef prices are higher than those of cattle price although the difference is quite small.

Table 5.5: Summary descriptive of the Estimated Speed of Adjustments.

\begin{tabular}{|c|c|c|c|c|}
\hline ECT & Mean & Minimum & Maximum & $\begin{array}{c}\text { Number of } \\
\text { Significant Adjustment }\end{array}$ \\
\hline \hline Retail Beef Price & 0.059 & 0.021 & 0.410 & 21 \\
\hline Cattle Price & 0.053 & 0.018 & 0.733 & 22 \\
\hline Both Prices & & & & 16 \\
\hline
\end{tabular}

Source: Own Calculation.

\subsection{Conclusions}

The empirical finding suggests that the elasticity of price transmission between cattle price and retail beef price in the Indonesian beef industry is less than one i.e. 0.42. The magnitude of the speed of adjustments serves as an indication of price rigidity, both for the cattle price and the retail beef price, implying that both prices tend to react slowly to any changes in the market. This low price transmission between the cattle price and retail beef price may also reflect a high marketing cost which is resulted from an inefficient market. The situation in which a lot of intermediaries along the supply chain as well as undeveloped marketing infrastructure in the Indonesian beef industry can be the reasons for these findings. Policy variables are found to significantly influence long-run equilibrium in the beef industry, suggesting that price rigidity, to some extent, is associated with policy intervention. Finally, our findings have also revealed that the Indonesian beef industry is classified as an imperfect market structure. 


\section{Chapter 6}

\section{Evaluating the Impact of Regional Trade Quota in Beef Price Formation}

\subsection{Introduction}

This section examines the role of regional trade quota policies in determining Indonesia's domestic beef price across the main cattle producing areas. Trade quota policy at the regional level limits the number of cattle that are allowed to be traded out of the respective regions. Such quota is imposed annually by the regional government based on the beef supply and demand prediction in an attempt to protect the domestic beef supply, particularly when it comes to the matter of price increase. A relatively significant increase in price stimulates over trading and over slaughtering practices of live cattle in the producer regions. In addition, as a general rule, a trade quota policy will be introduced when the prediction of cattle population growth is lower than the beef consumption rate in the region for a given period of time. Despite all of its advantages, the trade quota policy has raised some debates among scholars, especially concerning whether such a policy would potentially introduce negative effects to market integration. In a well-functioning and integrated market, the price differences between markets will be bounded by trade costs so that an arbitrage process will exist through an intra-regional trade. Therefore, in the presence of the trade-impeding policy, the arbitrage would be hindered and this situation might lead to the possible large sustained price differences between the regions. In addition, imposing trade quota may lead to increasing prices which can endanger the consumers, particularly during 
the peak demand season.

\subsection{Methodology}

To investigate the role of regional trade quota policies in price formation of beef, this study constructs trade pairs based on the information of trade flows data. Considering data availability issues, this study focuses on exploring 97 trade pairs which consist of the main producer areas from 32 provinces of Indonesia. The period analysis begins from 2008 until 2015. All variables are monthly series and transformed into logarithmic form. An empirical model is set up using a panel regression model as defined:

$$
\begin{array}{r}
P r_{i t}=\theta_{0}+\theta_{1} P f_{i t}+\theta_{2} T C+\theta_{3} f u e l+\theta_{4} \text { distance }+ \\
\theta_{5} \text { Quota }+\theta_{6} \text { QuotaTC }+ \text { month }+u_{i t}
\end{array}
$$

where $P r_{i t}$ represents the retail beef price in importing region $i$ at period time $t$, and $P f_{i t}$ represents the cattle price in exporting regions $i$ at period time $t$, and $u_{i t}$ is the error term. TC stands for the trade costs which are constructed based on the transportation cost index. Other variables representing the trade cost are also included, namely, fuel price represented by fuel and distance between importing and exporting regions. Meanwhile, the effect of the trade quota policy is explicitly represented as a dummy variable, namely Quota, whose value is 1 if the exporting regions impose the quota policy, and zero otherwise. In addition, a monthly dummy is also included in the model to capture seasonality as represented by month.

Generally speaking, in the presence of non-stationary variables, the estimation using standard panel fixed effect can produce biased results. Considering the data have a high time series dimension with $t=96$ and $n=90$, we estimate the model using a panel cointegration approach. In a panel data setting with non-stationary variables, there are two popular estimation methods, namely, 1) Fully Modified Ordinary Square (FMOLS) and 2) Dynamic Ordinary Least Square $(D O L S)$. These two estimation methods are preferable since they can be applicable regardless of whether the variables are stationary or cointegrated i.e. I(1). Therefore, we can allow both stationary and non-stationary variables to coexist in the same equation.

The FMOLS was originally introduced by Phillips and Hansen (1990) which modifies the least square estimation by taking into account 
serial correlation effects and endogeneity in the regressors as commonly results from a cointegrated relationship. In the case of stationary regressors, the FMOLS have the same limit theory as $O L S$, while for non-stationary variables, they are asymptotically equivalent with the maximum likelihood estimates of the cointegrating matrix. The details equation and assumptions of FMOLS can be seen in Phillips and Hansen (1990), Phillips (1993), Pedroni (1997), and Phillips and Moon (1999).

Meanwhile, the DOLS estimator was introduced by Kao and Chiang (1999) as an extension of the Stock and Watson (1993) estimator. In principle, the DOLS estimator augments the regression with the lead, and lags, as well as the contemporaneous values of the regressors in the first differences. Suppose we have a panel model with fixed effect:

$$
y_{i t}=\alpha_{i}+x^{\prime}{ }_{i t} \beta+u_{i t}, i=1, \ldots, N, t=1, \ldots, T
$$

where $y_{i t}$ is a matrix of $1 x_{1}, \beta$ is a vector of parameters with $(k, 1)$ dimension, $\alpha_{i}$ represents the individual effect, and $u_{i t}$ is the error term. Considering the $x_{i t}(k, 1)$ vector has an autoregressive process of the first difference such that: $x_{i t}=x_{i t}-1+\epsilon_{i t}$, then the DOLS estimator is derived as:

$$
y_{i t}=\alpha_{i}+x^{\prime}{ }_{i t} \beta+\sum_{j=q_{1}}^{j=q_{2}} c_{i j} \Delta x_{i t}+j+v_{i t}
$$

where $c_{i j}$ is the coefficient of leads or lags of the first difference of the explanatory variables. Compared to $F M O L S$, as explained by Wagner and Hlouskopa (2010), in most cases, the DOLS can outperform the FMOLS.

\subsection{Findings}

Table 6.1 summarizes the results of the estimated coefficient by panel regression models using three different estimation techniques. As shown in Table 6.1, it suggests a similar pattern. As a general picture, all of the estimated coefficients have the expected signs. Meanwhile, it is found that the cointegration models, both $D O L S$ and $F M O L S$, generally suggest higher magnitude than the $R E-G L S$ model. The estimated intercept is only found to be statistically significant the $R E-G L S$ model. Similar findings are also suggested in the month dummy variable. In addition, surprisingly, the transportation cost variable $(T C)$ is not found to be statistically significant for all cases.

Investigating the effect of trade quota policy, all three developed panel models produce a statistically significant estimated coefficients of the quota 


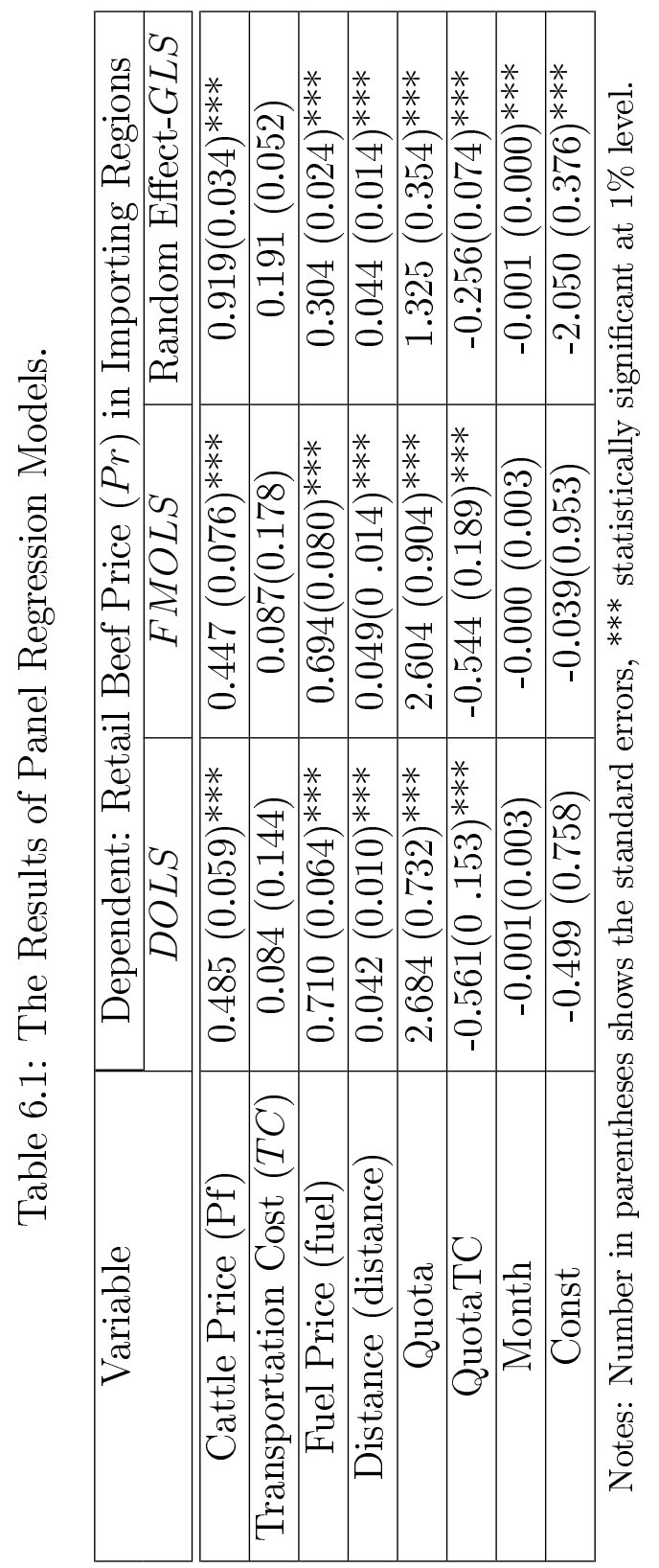


policy at the $1 \%$ level with a positive sign. The cointegration models, both DOLS and FMOLS estimators, show similar results for both magnitude and signs, while the $R E-G L S$ model results in lower magnitude. However, since the variable is constructed as a dummy variable, the interpretation of the magnitude of the estimated coefficient is not straight forward. Nevertheless, it can reveal that the trade quota policy has a positive and significant effect on the retail beef price in Indonesia as expected. The presence of a regional trade quota policy will consequently restrict the beef trade outside the exporting region, and thus may reduce the beef supply in the importing regions. As a result, ceteris paribus, the beef price in the importing regions will likely increase.

Another interesting finding relates to the role of trade quota in the Indonesian beef market. As shown in Table 6.1, the estimated coefficient of the dummy interaction i.e. QuotaTC is found to be statistically significant at the $1 \%$ level with a negative sign. As an interaction term, the estimated coefficient can be interpreted as a partial effect of the quota policy on the $T C$ variable. The cointegration models suggest effects of around $50 \%$ of the policy on the $T C$ variable, while the $R E-G L S$ model proposes lower number i.e. $25 \%$, ceteris paribus. According to the results, it can be revealed that the presence of a trade quota policy will simultaneously reduce the effect of the $T C$ variable on the retail beef price. However, the reason for this result remains puzzling. There is no underlying economic theory which depicts a clear relationship between trade quota and transportation costs. One possible explanation is that when a region imposes a trade quota policy, the probability to import the cattle outside the region is reduced and, as a consequence, cattle producers can maintain lower transportation costs in absolute number.

Besides assessing the effect of trade quota policy, according to the results, some variables which relate to trade costs are also investigated. The findings strongly suggest the effect of fuel price on the retail beef price. The coefficient can be interpreted as an elasticity of the fuel price on retail beef price, implying that if the fuel price increases by $1 \%$, then the beef price will likely increase by $0.70 \%$, on average, ceteris paribus. Furthermore, we can see the effect of the distance variable which can also be a proxy for the trade cost, though the effect is found to be statistically significant in all estimations, but the magnitude is much lower compared to the effect of the fuel price i.e. only $4 \%$. Therefore, in general, the findings propose that the fuel price plays a dominant role in the beef price formation which may influence the whole transaction costs in the industry. 


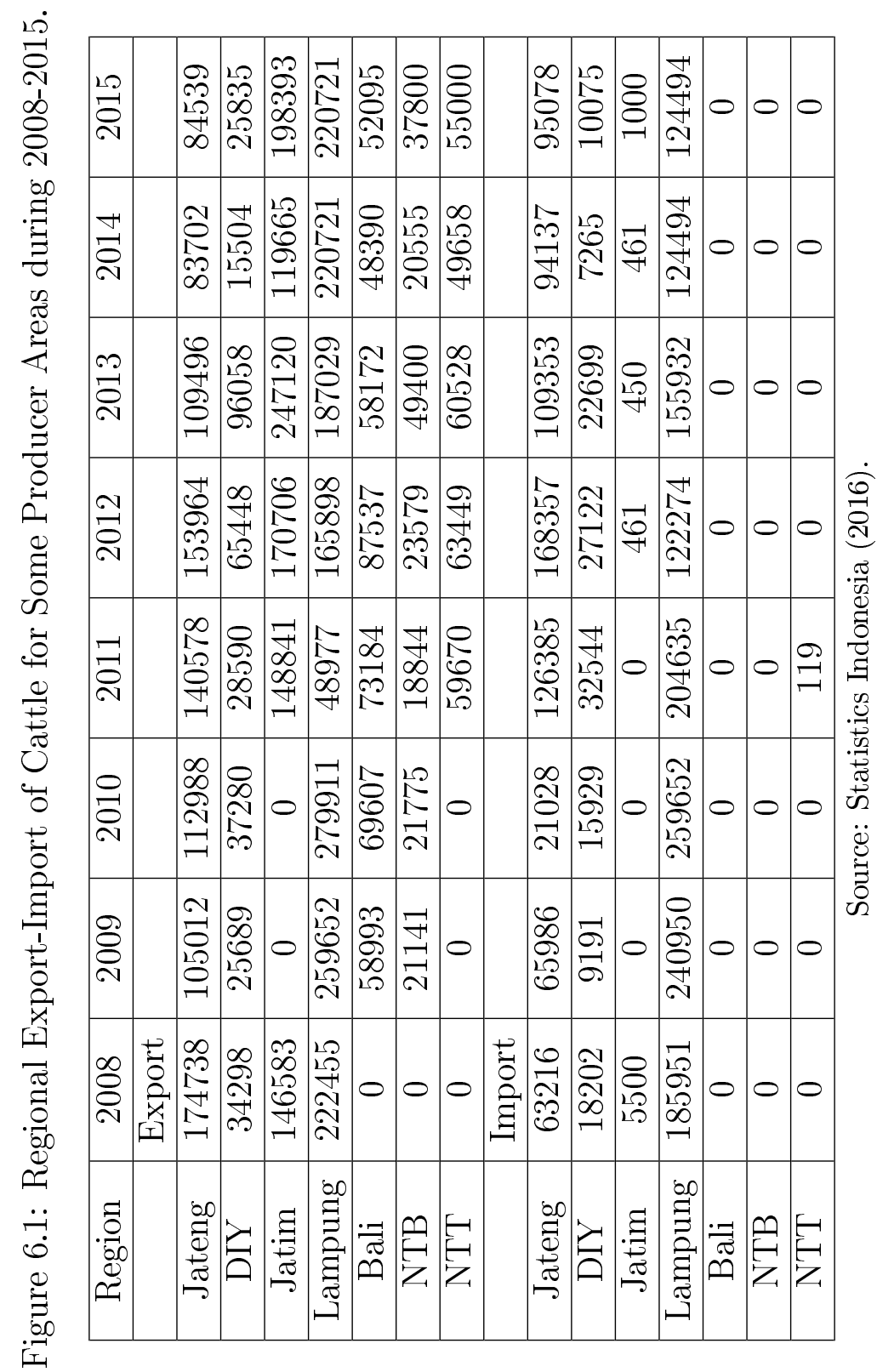


When it comes to the relationships between the cattle price in the exporting regions and the retail beef price in the importing regions, the empirical findings are a little bit puzzling. The cointegration models, both $D O L S$ and FMOLS, suggest the price elasticity is less than one which is only around $45 \%$, while the $R E-G L S$ model suggests the price elasticity is close to one. In a market integration framework, a price elasticity close to one reflects that the market is integrated in which the price in one market location or market chain will be perfectly transmitted to another market location as well as the market chain. Considering the case of the Indonesian beef industry, where a lack of marketing infrastructure is common, the findings suggested by the cointegration models are found to be more plausible.

\subsection{Conclusions}

By using a panel cointegration model with FMOLS and DOLS estimators, this study finds that the regional trade quota policy imposed by the government in the main producer areas is found to significantly affect the price formation in the Indonesian beef industry. As expected, the effect of this trade quota policy is positive which means that the policy will likely increase the retail beef price. Restricting the quantity of product that can be traded will lead to a limited supply in the importing regions. Consequently, if the demand remains unchanged, prices will simultaneously go up. Besides affecting the retail beef price, the empirical findings also suggest the role of this trade quota policy in the trade costs. However, the relationship is negative which implies that imposing a trade quota policy will reduce the effect of trade costs on the retail beef price. Another findings associated with the role of trade costs on the retail beef price formation is that fuel price plays a dominant role, despite the significant effect of distance as a proxy for the trade costs. Furthermore, the results from the panel cointegration model suggest low price transmission between the retail beef price in the importing regions and the cattle price in the exporting regions i.e. around $45 \%$. 


\section{Chapter 7}

\section{Concluding Remarks}

In the food economy, government intervention highlights the market profile in many developing countries. This study provides empirical evidences on the role of governmental policy in price formation with the case of the Indonesian beef industry between 2002 and 2015 periods. Within the beef market, there are several types of intervention policies imposed by the Indonesian government at national and regional level. At national level, interventions are mainly related to the import regulations, while at regional level, a trade quota policy are imposed by several main beef producer regions. Following the government's ambition to achieve self-sufficiency status which has been officially declared in 2010, Indonesian government has pursued to reduce import on beef products dramatically. Besides that, as a response to increasing demand, the government also attempts to maintain stable price. With regard to these issues, some changes have been introduced in the import regulation.

The empirical findings support the existence of market integration not only between Indonesia and the world market, but also among Indonesian domestic beef markets. However, it is important to note that the degree of integration is shown by a relatively slow price transmission among the markets. The first analysis suggests that only the domestic price conducts the adjustment from the long run disequilibrium with the world market. In addition, the estimated thresholds indicate that importing beef is efficient particularly for Jakarta and West Java markets. The second analysis shows that the pattern of market interdependence confirms the trade pattern among the investigated markets, and thus emphasize the role of tradability in the spatial market integration. The third analysis also presents the low price transmission between retail beef prices and cattle prices. 
All analyses consistently emphasize the role of policy intervention in price transmission which produces similar results. The results of first analysis prove that the price reference policy is more effective than the import restrictions imposed as part of the self-sufficiency regulation in the price transmission between domestic and import prices. Meanwhile, the second analysis finds a significant effect of price reference policy in three producer regions i.e. JTM, Bali, and NTT with different effects both in the sign and the magnitude. Similarly, the third analysis also supports the role of policy intervention in the price transmission between retail beef prices and cattle prices. Accordingly, regional trade quota policy imposed by the government in the main producer areas is found to be significantly affecting the price formation in Indonesian beef industry as well. As expected, the effect of this trade quota policy is positive which means that the policy will likely increase the retail beef price. To conclude, the overall findings suggest that policy interventions in the Indonesian beef industry have resulted in lowering price transmission among beef prices.

In the food sector, achieving self-sufficiency status and maintaining stable price are the main interest for governments particularly in developing countries. However, to formulate a right policy which can benefit all actors in the economy is not an easy task. When price increases dramatically, the government usually conducts a market operation. In the case of Indonesian beef industry, this action is commonly used by importation. However, there is no guarantee that price increase are truly reflecting insufficient supply or it is due to the unfair market system. Given the situation, in which the marketing infrastructure is under developed and hence results to a high transaction cost, managing a temporary policy may come at cost. High transaction cost cannot only harm the consumer but also lead to more opportunities to an unlawful arbitrage and rent seeking behavior. On the other hand, lowering import restriction is arguably to harm the smallholders which are less competitive. Therefore, in the case of Indonesian beef industry, investment for the development of marketing infrastructure should become a priority along with the improvement of productivity. In addition, a producer-oriented policy measures should be more emphasized.

We acknowledge several limitations in this study. First, we are compelled to use parsimonious model specification both in $V E C M$ and $T V E C M$. Second, the use of retail beef price for investigating spatial market integration may not be the best choice to capture spatial arbitrage activities. The use of wholesale price may be better in this regard. In 
addition, the employment of aggregate data in this study neglects differences in the quality of beef products. From the estimation technique, it is always challenging to produce unbiased estimates as well as a meaningful economic interpretation at the same time. Therefore, in this study, we acknowledge that our assumptions e.g. assuming one long run relationship for the industry (in Chapter 5) may be over general. With regard to panel data analysis, we recommend to take into account the issue of cross section dependence. Finally, assessing the impact of policy requires a valid understanding about how the policy is truly functioning, though it remains unclear to be captured in the empirical work. 


\section{Appendix}

\section{A Summary Statistics of Retail Beef Prices}

\begin{tabular}{|c|c|c|c|c|}
\hline Province & Mean & Std. Dev. & Min & Max \\
\hline \hline NAD & 91434.53 & 13535.86 & 71500 & 119142 \\
\hline Sumut & 74870.9 & 12727 & 57909 & 103806 \\
\hline Sumbar & 76377.72 & 15200.6 & 54522 & 105810 \\
\hline Riau & 76153.1 & 14773.38 & 53156 & 107601 \\
\hline Jambi & 81822.79 & 18764.86 & 55556 & 118327 \\
\hline Sumsel & 80055.97 & 19900.31 & 52421 & 119648 \\
\hline Bengkulu & 76354.18 & 14960.56 & 58000 & 107531 \\
\hline Lampung & 76982.72 & 21558.3 & 6604 & 116985 \\
\hline Babel & 83280.06 & 17315.34 & 59543 & 112676 \\
\hline Kepri & 80239.53 & 14708.81 & 54333 & 115295 \\
\hline Jawa Barat & 71852.86 & 15939.76 & 49305 & 107712 \\
\hline Jawa Tengah & 69840.47 & 16187.21 & 45897 & 98017 \\
\hline DIY & 72440.65 & 16991.75 & 49579 & 102495 \\
\hline Jawa Timur & 67593.65 & 16851.47 & 43510 & 97359 \\
\hline Banten & 77008.14 & 17367.4 & 50375 & 105758 \\
\hline Bali & 63593.81 & 21058 & 39455 & 98795 \\
\hline NTB & 64275.98 & 13715.71 & 40579 & 91871 \\
\hline NTT & 61398.17 & 16149.76 & 33545 & 85854 \\
\hline Kalbar & 85764.7 & 20562.74 & 60474 & 130089 \\
\hline Kalteng & 86709.06 & 18465.48 & 58826 & 116803 \\
\hline Kalsel & 87364.82 & 23473.98 & 7260 & 130476 \\
\hline Kaltim & 88505.14 & 22929.65 & 7649 & 127008 \\
\hline & & & &
\end{tabular}

Source: Statistics Indonesia (2015). 


\begin{tabular}{|c|c|c|c|c|}
\hline Province & Mean & Std. Dev. & Min & Max \\
\hline \hline Sulut & 66660.38 & 14174.12 & 45400 & 96412 \\
\hline Sulteng & 70098.13 & 9994.974 & 50400 & 88383 \\
\hline Sulsel & 68905.35 & 11304.79 & 46692 & 92175 \\
\hline Sultra & 69241.31 & 13865.79 & 50133 & 93574 \\
\hline Gorontalo & 65413.61 & 12814.29 & 45938 & 93294 \\
\hline Sulbar & 70195.48 & 12959.39 & 51250 & 97760 \\
\hline Maluku & 61507.25 & 10266.21 & 43889 & 79532 \\
\hline Maluku Utara & 73102.06 & 16509.39 & 45875 & 106901 \\
\hline Papua Barat & 75912.48 & 11217.8 & 57500 & 96837 \\
\hline Papua & 89953.85 & 23410.14 & 59000 & 143622 \\
\hline
\end{tabular}

Source: Statistics Indonesia (2015). 


\section{B Summary Statistics of Cattle Prices}

\begin{tabular}{|c|c|c|c|c|}
\hline Province & Mean & Std. Dev. & Min & Max \\
\hline NAD & 9592399 & 1540822 & 6500000 & $1.28 \mathrm{e}+07$ \\
\hline Sumut & 9063505 & 1485514 & 6921667 & $1.24 \mathrm{e}+07$ \\
\hline Sumbar & $1.00 \mathrm{e}+07$ & 1665638 & 6227273 & $1.27 \mathrm{e}+07$ \\
\hline Riau & 9637823 & 1840046 & 5500000 & $1.27 \mathrm{e}+07$ \\
\hline Jambi & $1.13 \mathrm{e}+07$ & 1943502 & 6500000 & $1.38 \mathrm{e}+07$ \\
\hline Sumsel & 8924923 & 1304428 & 5566667 & $1.11 \mathrm{e}+07$ \\
\hline Bengkulu & $1.00 \mathrm{e}+07$ & 1963432 & 6000000 & $1.38 \mathrm{e}+07$ \\
\hline Lampung & 7849400 & 1133311 & 6108334 & $1.06 \mathrm{e}+07$ \\
\hline Babel & $1.02 \mathrm{e}+07$ & 2329438 & 6338462 & $1.50 \mathrm{e}+07$ \\
\hline Kepri & 9915022 & 1220256 & 6333334 & $1.23 \mathrm{e}+07$ \\
\hline Jawa Barat & 9390306 & 1919219 & 6025000 & $1.37 \mathrm{e}+07$ \\
\hline Jawa Tengah & 7565329 & 1501776 & 5545582 & $1.11 \mathrm{e}+07$ \\
\hline DIY & 6637526 & 1050842 & 5443590 & 8980184 \\
\hline Jawa Timur & 8367203 & 1781675 & 5703485 & $1.25 \mathrm{e}+07$ \\
\hline Banten & 8709975 & 2087782 & 6400000 & $1.44 \mathrm{e}+07$ \\
\hline Bali & 5788474 & 1072732 & 4410000 & 8081351 \\
\hline NTB & 5789909 & 1053101 & 4000000 & 8099917 \\
\hline NTT & 6461475 & 861743.6 & 4500000 & 7701924 \\
\hline Kalbar & 6681398 & 2238672 & 4366667 & $1.25 \mathrm{e}+07$ \\
\hline Kalteng & 8319107 & 1565359 & 5100000 & $1.20 \mathrm{e}+07$ \\
\hline Kalsel & 7515623 & 1769432 & 4950000 & $1.13 \mathrm{e}+07$ \\
\hline Kaltim & 8738326 & 1875068 & 5625000 & $1.29 \mathrm{e}+07$ \\
\hline
\end{tabular}

Source: Statistics Indonesia (2015). 


\begin{tabular}{|c|c|c|c|c|}
\hline Province & Mean & Std. Dev. & Min & Max \\
\hline \hline Sulut & 9118630 & 1572982 & 5250000 & $1.11 \mathrm{e}+07$ \\
\hline Sulteng & 7090124 & 1428206 & 4125000 & 9074695 \\
\hline Sulsel & 7867234 & 1438175 & 4636539 & $1.07 \mathrm{e}+07$ \\
\hline Sultra & 5763667 & 1000545 & 1167531 & 7701431 \\
\hline Gorontalo & 6859002 & 604562.3 & 5287500 & 8114681 \\
\hline Sulbar & 7820806 & 1149896 & 3965000 & 9568934 \\
\hline Maluku & 5910907 & 1376802 & 3500000 & 8417811 \\
\hline Maluku Utara & 6874616 & 1423902 & 3608333 & 9280563 \\
\hline Papua Barat & 8583792 & 1571904 & 5275000 & $1.07 \mathrm{e}+07$ \\
\hline Papua & 7842392 & 721252.8 & 6008334 & 9169456 \\
\hline
\end{tabular}

Source: Statistics Indonesia (2015). 


\section{The Estimated Speed of Adjustment}

\begin{tabular}{|c|c|c|c|c|}
\hline Province & ec_pr & ec_pf & pr_adjust & pf_adjust \\
\hline \hline NAD & 0,0212431 & 0,0432567 & 1 & 1 \\
\hline Sumut & 0,0269743 & 0,0183503 & 1 & 1 \\
\hline Sumbar & 0,0264098 & 0,0681703 & 1 & 1 \\
\hline Riau & 0,0479096 & 0,0553998 & 1 & 1 \\
\hline Jambi & 0,0363843 & 0,0440562 & 1 & 1 \\
\hline Sumsel & 0,0584909 & 0,0569465 & 1 & 1 \\
\hline Bengkulu & 0,0394895 & 0,0536121 & 1 & 1 \\
\hline Lampung & 0,3515906 & 0,024768 & 1 & 0 \\
\hline Babel & 0,0548495 & 0,0248366 & 1 & 0 \\
\hline Kep. Riau & 0,000084 & 0,0353551 & 0 & 0 \\
\hline Jawa Barat & 0,0456139 & 0,0406475 & 1 & 1 \\
\hline Jawa Tengah & 0,0309248 & 0,0218099 & 1 & 1 \\
\hline DI Yogya & 0,0246874 & 0,0250424 & 1 & 0 \\
\hline Jawa Timur & 0,0310351 & 0,0351067 & 1 & 1 \\
\hline Banten & 0,0841085 & 0,0369193 & 1 & 1 \\
\hline Bali & 0,0222447 & 0,0200062 & 1 & 0 \\
\hline NTB & 0,0615688 & 0,0479197 & 1 & 1 \\
\hline NTT & 0,0026007 & 0,0498081 & 0 & 1 \\
\hline Kalbar & 0,0428412 & 0,0482344 & 1 & 1 \\
\hline Kalteng & 0,0344724 & 0,0474161 & 1 & 1 \\
\hline Kalsel & 0,3774093 & 0,0197583 & 1 & 0 \\
\hline Kaltim & 0,410574 & 0,0364517 & 1 & 1 \\
\hline
\end{tabular}

Source: Statistics Indonesia (2015). 


\begin{tabular}{|c|c|c|c|c|}
\hline Province & ec_pr & ec_pf & pr_adjust & pf_adjust \\
\hline \hline Sulut & 0,0622516 & 0,0664959 & 1 & 1 \\
\hline Sulteng & 0,0131586 & 0,020302 & 0 & 0 \\
\hline Sulsel & 0,0121822 & 0,0301384 & 0 & 1 \\
\hline Sultra & 0,0149461 & 0,7327888 & 0 & 1 \\
\hline Gorontalo & 0,0143514 & 0,0231097 & 0 & 0 \\
\hline Sulbar & 0,0133756 & 0,0082028 & 0 & 0 \\
\hline Maluku & 0,0369206 & 0,059093 & 0 & 1 \\
\hline Maluku Utara & 0,0099533 & 0,0424929 & 0 & 0 \\
\hline Papua Barat & 0,0197927 & 0,0920113 & 0 & 1 \\
\hline Papua & 0,0144274 & 0,0281432 & 0 & 1 \\
\hline
\end{tabular}

Source: Statistics Indonesia (2015). 


\section{Bibliography}

B. O. Abidoye and M. Labuschagne. The transmission of world maize price to south african maize market: a threshold cointegration approach. Agricultural Economics, 45(4):501-512, 2014.

F. Asche, O. Flaaten, J. R. Isaksen, and T. Vassdal. Derived demand and relationships between prices at different levels in the value chain: A note. Journal of Agricultural Economics, 53(1):101-107, 2002.

Z. Bakucs, J. Falkowski, and I. Fertô. Does market structure influence price transmission in the agro-food sector? a meta-analysis perspective. Journal of Agricultural Economics, 65(1):1-25, 2014.

Z. Bakucs and I. Fertô. Marketing margins and price transmission on the hungarian pork meat market. Agribusiness, 21(2):273-286, 2005.

Z. Bakucs, I. Fertő, and J. Falkowski. What causes asymmetric price transmission in agro-food sector? meta-analysis perspective. IEHAS Discussion Papers 1303, Institute of Economics, Centre for Economic and Regional Studies, Hungarian Academy of Sciences, 2013.

N. Balke and T. Fomby. Threshold cointegration. International Economic Review, 38(3):627-45, 1997.

B. Baltagi and C. Kao. Nonstationary panels, cointegration in panels and dynamic panels: A survey. Center for Policy Research Working Papers 16, Center for Policy Research, Maxwell School, Syracuse University, 2000.

C. Barrett and J. R. Li. Distinguishing between equilibrium and integration in spatial price analysis. American Journal of Agricultural Economics, 84(2):292-307, 2002.

C. B. Barrett. Spatial market integration. 2008. 
J.-C. Bizimana, J. P. Angerer, D. A. Bessler, and F. Keita. Cattle markets integration and price discovery: The case of mali. The Journal of Development Studies, 51(3):319-334, 2015.

Y. Bolotova and A. M. Novakovic. The impact of the new york state retail milk price regulation on farm-to-retail price transmission and supermarket pricing strategies in metropolitan fluid milk markets. 2011 Annual Meeting, July 24-26, 2011, Pittsburgh, Pennsylvania 104514, Agricultural and Applied Economics Association, 2011.

X. Cirera and C. Arndt. Measuring the impact of road rehabilitation on spatial market efficiency in maize markets in mozambique. Agricultural Economics, 39(1):17-28, 2008.

P. L. Fackler and B. Goodwin. Spatial price analysis. In B. L. Gardner and G. C. Rausser, editors, Handbook of Agricultural Economics, volume 1, Part 2, chapter 17, pages 971-1024. Elsevier, 1 edition, 2001.

A. Falsafian, R. Moghaddasi, et al. Spatial integration and asymmetric price transmission in selected iranian chicken markets. In Presentation at the 12th European Agricultural Economics Congress, Gent, Belgium, 2008.

M. Friedman. Price theory. Transaction Publishers, 2007.

B. L. Gardner. The farm-retail price spread in a competitive food industry. American Journal of Agricultural Economics, 57(3):399-409, 1975.

P. George and G. A. King. Consumer Demand for Food Commodities in the United States with Projections for 1980. University of California, Davis, Giannini Foundation, 1971.

G. Gonzalez-Rivera and S. Helfand. The extent, pattern, and degree of market integration: A multivariate approach for the brazilian rice market. American Journal of Agricultural Economics, 83(3):576-592, 2001.

B. Goodwin and N. E. Piggott. Spatial market integration in the presence of threshold effects. American Journal of Agricultural Economics, 83(2):302$317,2001$.

L. Götz, T. Glauben, and B. Brümmer. Wheat export restrictions and domestic market effects in russia and ukraine during the food crisis. Food Policy, 38(C):214-226, 2013. 
F. Greb, T. Krivobokova, A. Munk, and S. von Cramon-Taubadel. Regularized bayesian estimation in generalized threshold regression models. Courant Research Centre: Poverty, Equity and Growth - Discussion Papers 99, Courant Research Centre PEG, 2012.

F. Greb, T. Krivobokova, A. Munk, and S. von Cramon-Taubadel. Regularized bayesian estimation of generalized threshold regression models. Bayesian Anal., 9(1):171-196, 032014.

F. Greb, S. von Cramon-Taubadel, T. Krivobokova, and A. Munk. The estimation of threshold models in price transmission analysis. American Journal of Agricultural Economics, 2013.

W. F. Hahn, H. Stewart, D. P. Blayney, and C. G. Davis. Modeling Price Transmission between Farm and Retail Prices: A Soft Switches Approach. 2015 AAEA \& WAEA Joint Annual Meeting, July 26-28, San Francisco, California 204951, Agricultural and Applied Economics Association;Western Agricultural Economics Association, May 2015.

B. Hansen and B. Seo. Testing for two-regime threshold cointegration in vector error-correction models. Journal of Econometrics, 110(2):293-318, 2002.

I. Hassouneh, S. von Cramon-Taubadel, T. Serra, and J. M. Gil. Recent developments in the econometric analysis of price transmission. TRANSFOP (Transparency of Food Pricing) Working Paper, (2), 2012.

R. Ihle, B. Brümmer, and S. R. Thompson. Structural change in european calf markets: decoupling and the blue tongue disease. European Review of Agricultural Economics, 39(1):157-180, 2012.

N. Jamora and S. von Cramon-Taubadel. Transaction cost thresholds in international rice markets. Journal of Agricultural Economics, 67(2):292307, 2016.

C. Kao. Spurious regression and residual-based tests for cointegration in panel data. Journal of Econometrics, 90(1):1-44, 1999.

C. Kao and M.-H. Chiang. On the estimation and inference of a cointegrated regression in panel data. Econometrics, EconWPA, 1997.

C. Kao and S. McCoskey. A residual-based test of the null of cointegration in panel data. Econometrics, EconWPA, 1997. 
H. Kim and R. Ward. Price transmission across the u.s. food distribution system. Food Policy, 41(C):226-236, 2013.

H. Kinnucan and D. Zhang. Notes on farm-retail price transmission and marketing margin behavior. Agricultural Economics, 46(6):729-737, 2015.

T. Lloyd, S. McCorriston, C. Morgan, and A. Rayner. The impact of food scares on price adjustment in the uk beef market. Agricultural Economics of Agricultural Economists, 25(2-3), 2001.

S. McCorriston, C. W. Morgan, and A. J. Rayner. Processing technology, market power and price transmission. Journal of Agricultural Economics, 49(2):185-201, 1998.

K. McNew. Spatial market integration: Definition, theory, and evidence. Agricultural and Resource Economics Review, 25(1):1-11, 0041996.

J. Meyer and S. von Cramon-Taubadel. Asymmetric price transmission: A survey. Journal of Agricultural Economics, 55(3):581-611, 2004.

P. Pedroni. Panel cointegration; asymptotic and finite sample properties of pooled time series tests, with an application to the ppp hypothesis; new results. working paper, 1997.

P. Pedroni. Critical values for cointegration tests in heterogeneous panels with multiple regressors. Oxford Bulletin of Economics and Statistics, 61(0):653-70, 1999.

P. Pedroni. Panel cointegration: Asymptotic and finite sample properties of pooled time series tests with an application to the ppp hypothesis. Econometric Theory, 20(03):597-625, 2004.

S. Peltzman. Prices rise faster than they fall. Journal of Political Economy, 108(3):466-502, 2000.

H. M. Pesaran, Y. Shin, and R. P. Smith. Pooled Mean Group Estimation of Dynamic Heterogeneous Panels. Journal of the American Statistical Association, 94(446):621-634, 1999.

P. Phillips and B. Hansen. Statistical inference in instrumental variables regression with i(1) processes. Review of Economic Studies, 57(1):99-125, 1990. 
P. Phillips and H. Moon. Linear regression limit theory for nonstationary panel data. Cowles Foundation Discussion Papers 1222, Cowles Foundation for Research in Economics, Yale University, 1999.

P. C. Phillips. Fully Modified Least Squares and Vector Autoregression. Cowles Foundation Discussion Papers 1047, Cowles Foundation for Research in Economics, Yale University, May 1993.

R. J. Sexton and N. Lavoie. Food processing and distribution: An industrial organization approach. In B. L. Gardner and G. C. Rausser, editors, Handbook of Agricultural Economics, volume 1, Part 2, chapter 15, pages 863-932. Elsevier, 1 edition, 2001.

J. Stock and M. Watson. A simple estimator of cointegrating vectors in higher order integrated systems. Econometrica, 61(4):783-820, 1993.

R. Valdes, S. Von Cramon-Taubadel, and A. Engler. Transaction costs and trade liberalization: An empirical perspective from the mercosur agreement. Food Policy, 55(C):109-116, 2015.

T. Vollrath and C. Hallahan. Testing the integration of us-canadian meat and livestock markets. Canadian Journal of Agricultural Economics/Revue canadienne d'agroeconomie, 54(1):55-79, 2006.

M. Wagner and J. Hlouskova. The performance of panel cointegration methods: Results from a large scale simulation study. Econometric Reviews, 29(2):182-223, 2010.

J. Westerlund. Testing for error correction in panel data. Oxford Bulletin of Economics and Statistics, 69(6):709-748, 2007.

M. K. Wohlgenant. Marketing margins: Empirical analysis. Handbook of agricultural economics, 1:933-970, 2001. 